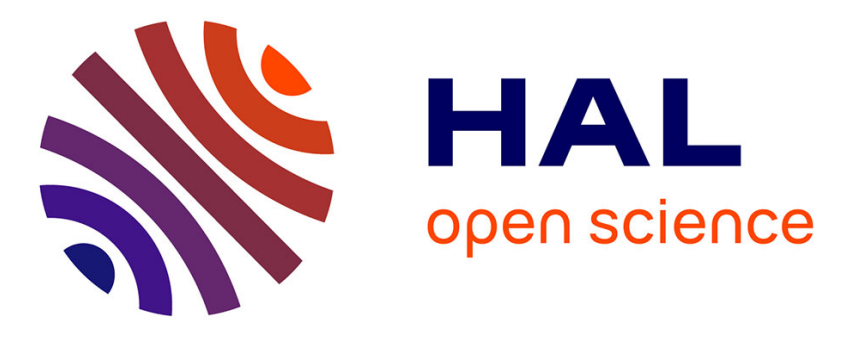

\title{
Modeling directional brightness temperature over a maize canopy in row structure
}

\author{
Tao Yu, Xingfa Gu, Guoliang Tian, Michel Legrand, Frédéric Baret, \\ Jean-François Hanocq, Roland Bosseno, Yong Zhang
}

\section{To cite this version:}

Tao Yu, Xingfa Gu, Guoliang Tian, Michel Legrand, Frédéric Baret, et al.. Modeling directional brightness temperature over a maize canopy in row structure. IEEE international geoscience and remote sensing symposium, Jul 2003, Toulouse, France. 10.1109/TGRS.2004.834196 . hal-02763400

\section{HAL Id: hal-02763400 \\ https: / hal.inrae.fr/hal-02763400}

Submitted on 22 Sep 2021

HAL is a multi-disciplinary open access archive for the deposit and dissemination of scientific research documents, whether they are published or not. The documents may come from teaching and research institutions in France or abroad, or from public or private research centers.
L'archive ouverte pluridisciplinaire HAL, est destinée au dépôt et à la diffusion de documents scientifiques de niveau recherche, publiés ou non, émanant des établissements d'enseignement et de recherche français ou étrangers, des laboratoires publics ou privés.

\section{(c)(1)}

Distributed under a Creative Commons Attribution| 4.0 International License 


\title{
Modeling Directional Brightness Temperature Over a Maize Canopy in Row Structure
}

\author{
Tao Yu, Xingfa Gu, Guoliang Tian, Michel Legrand, Frédéric Baret, Jean-François Hanocq, Roland Bosseno, and \\ Yong Zhang
}

\begin{abstract}
A study on modeling the variations of directional brightness temperature (DBT) for row-structure crops was carried out with the images captured by a large-aperture thermal infrared camera over a maize canopy. The model assumes that the DBT is a function of target component brightness temperatures and their directional fractions. The canopy has three brightness temperature components: the sunlit soil, the shaded soil, and the vegetation. Their fractions in the scene depend on the sun-view geometry and the distributions of gaps within and between plant rows. To describe canopy geometrical features, a series of porous hedgerows with a rectangular cross section is used. The directional variations of gap fractions are described by the Kuusk function. The model demonstrated how the features of DBT depend on the sun-view geometry, canopy geometrical structure, and component brightness temperatures. In the simulation of DBT over a middle-density canopy near the local noontime, the results revealed an evident row-direction-oriented hot stripe in DBT polar maps, where the hot spot appeared along the sun direction. The sensitivities of the model to the input parameters were tested. Further validation demonstrated a close correlation between predicted DBT and field observations.
\end{abstract}

Index Terms-Directional brightness temperature (DBT), geometric optical and radiative transfer (GORT) model, maize canopy, row structure.

\section{INTRODUCTION}

D IRECTIONAL brightness temperature (DBT) plays an important role in characterizing canopy thermal radiation distributions. As a parameter acquired by remote sensing instruments, DBT has been widely applied in many research areas, such as the estimation of field energy budget, the retrieval of field biophysical and phenological parameters, and the normalization of remote sensing information obtained at different directions or from different platforms, etc. [1]-[10]. In these experiments, row crop DBT variations have been observed, with the hot spot effects appearing in the solar principal plane when the sensor is near the direction of incident sunlight [2], [10]. Many researchers have observed that the magnitude and

T. Yu, G. Tian, and Y. Zhang are with State Key Laboratory of Remote Sensing Science, Institute of Remote Sensing Applications, Chinese Academy of Sciences, Beijing 100101, China.

X. Gu, F. Baret, and J.-F. Hanocq are with Institut National de la Recherche Agronomique, Climat Sol Environnement, 84914 Avignon, France.

M. Legrand is with Laboratoire d'Optique Atmosphérique, Université des Sciences et Technologies de Lille, 59655 Villeneuve d'Ascq, France.

R. Bosseno is with the Institut de Recherche Pour le Developpement, 34394 Montpellier Cedex 5, France.

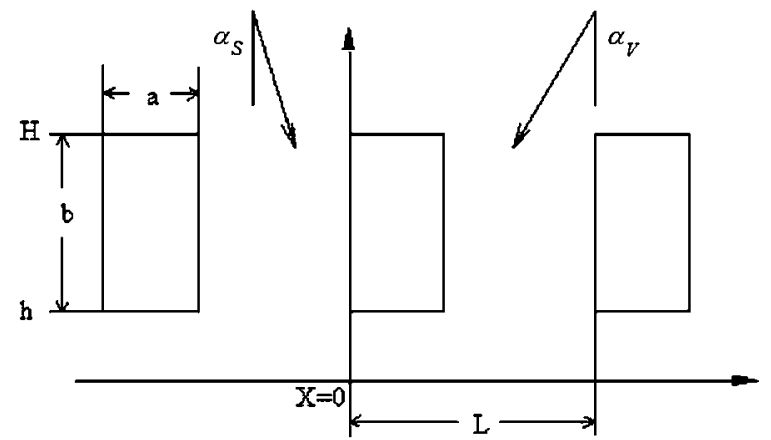

Fig. 1. Sun-maize canopy-sensor geometry and definition of variables as seen in the plane perpendicular to the row direction. The origin of $x$ is at the footprint of the left corner of one hedgerow. $\mathrm{H}$ and $\mathrm{h}$ are the heights of upper and bottom edge, respectively; $b$ is defined as hedgerow thickness $(b=H-h)$; $a$ is hedgerow width; $\mathrm{L}$ is row spacing. The sun and view directions projected in perpendicular plane of the rows are represented by their inclination angles $\alpha_{S}$ and $\alpha_{V}$, respectively.

angular variations of the DBT depended strongly on the temperature distributions and geometric structure over the canopy and the sun-target-sensor geometry [2], [5], [10]-[15]. To extend the practical benefit of remotely sensed data based on better understanding of canopy directional thermal radiative features, the physics-based quantitative descriptions of row crop DBT have been intensively studied for a long period.

The numerous physical models of row crop DBT could be generally classified into four types, which include: 1) geometrical-optics (GO) models; 2) hybrid geometric optical and radiative transfer (GORT) models, which combine GO and radiative transfer (RT) approaches; 3) computer/numerical simulation methods; and 4) the models derived from bidirectional reflectance distribution function (BRDF) kernel models [2], [11], [16]-[22]. Jackson et al. [2] developed a GO model for partially covered row crop canopies. It was validated and applied by Kimes et al. [11], [16] in the simulation of cotton DBT. To describe canopy geometric and thermal characteristics, plant rows were abstracted as extended opaque hedgerows. The canopy was assumed to have four brightness temperature components: the sunlit and shaded leaves, the sunlit and shaded soil. Each component had a unique brightness temperature. However, the effect of gaps within the plant rows was neglected. Kimes et al. [16] developed a GORT hybrid model that took into account the canopy architecture in computing the radiation transfer within the vegetation. Prévot [5] had improved this model for describing maize DBT at different growth periods, when the multiple diffusions among vegetation layers were investigated to describe the radiation budget of the canopy. To take account of the three-dimensional (3-D) architecture of vegetation covers and the angular cavity effect in the directional 


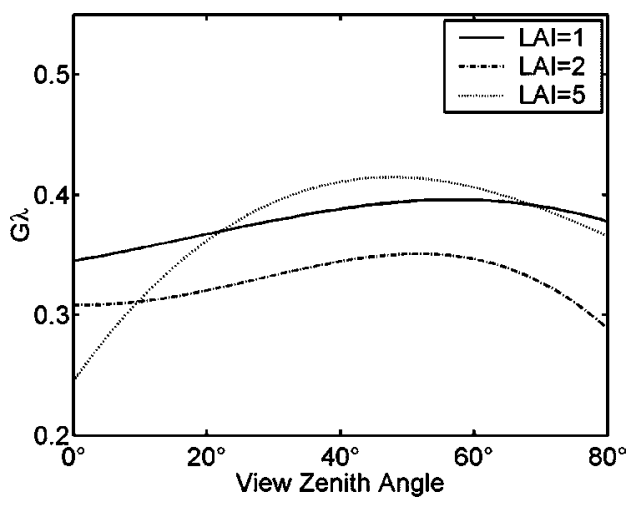

Fig. 2. Leaf attenuation parameter $G \lambda$ of maize canopy as the input of the model.

temperature, François et al. [21] derived a more complicated model to retrieve the component temperatures of the soil and the vegetation. The model, based on the research of Prévot [5], computed the canopy thermal radiance as a function of soil and leaf temperatures, canopy geometrical structures, and the view angles. However, this kind of model neglected the effect of row structures on the simulation of the canopy DBT. These 3-D ray tracing and radiosity models have also been used to demonstrate the complexity of the canopy structure coupling with the thermal directional radiation. Smith et al. [17] simulated the directional radiation based on a simplified canopy temperature distribution derived from the energy balance with scatting effect. Gastellu-Etchegorry et al. [20] presented a thermal infrared module in their discrete anisotropy radiative transfer (DART) model to study the field energy budget and diurnal variation of the DBT. While this kind of model needs very complicated information on the canopy architecture and temperature distributions. Many physics-based DBT models have been derived from BRDF models directly. Snyder et al. [18], [19] have modified several semiempirical BRDF models by extending the spectral range from visible and near-infrared spectral domain into the thermal infrared band by developing a lookup table for the Moderate Resolution Imaging Spectrometer land surface temperature algorithm. These models demonstrated a potential in row crop DBT studies with necessary modifications. The inversion of these models could also be used to provide the information on the canopy geometry and surface thermal radiation parameters.

In models concerning row crop DBT variations, the studies on the interaction between the sunlight and canopy geometrical structure have been emphasized because the canopy brightness temperature distribution and the canopy component fractions in the scene are determined by the gaps between and within the plant rows. Generally, the brightness temperature mainly depends on the element thermal property (vegetation or soil) and the sun shine condition (sunlit or shaded), which enables gap fractions to play an important role in the estimation of the canopy DBT [5], [11]-[13], [23].

Gap fraction is the probability a ray that is not intercepted by leaves and stems penetrates through the canopy [24], [25]. Its value depends on the leaf angle distribution and leaf spatial distribution within crowns, the crown shape, and plant spatial distribution over the field [1], [26]-[30], which reflects the essential influences of the canopy architecture on the crown and canopy

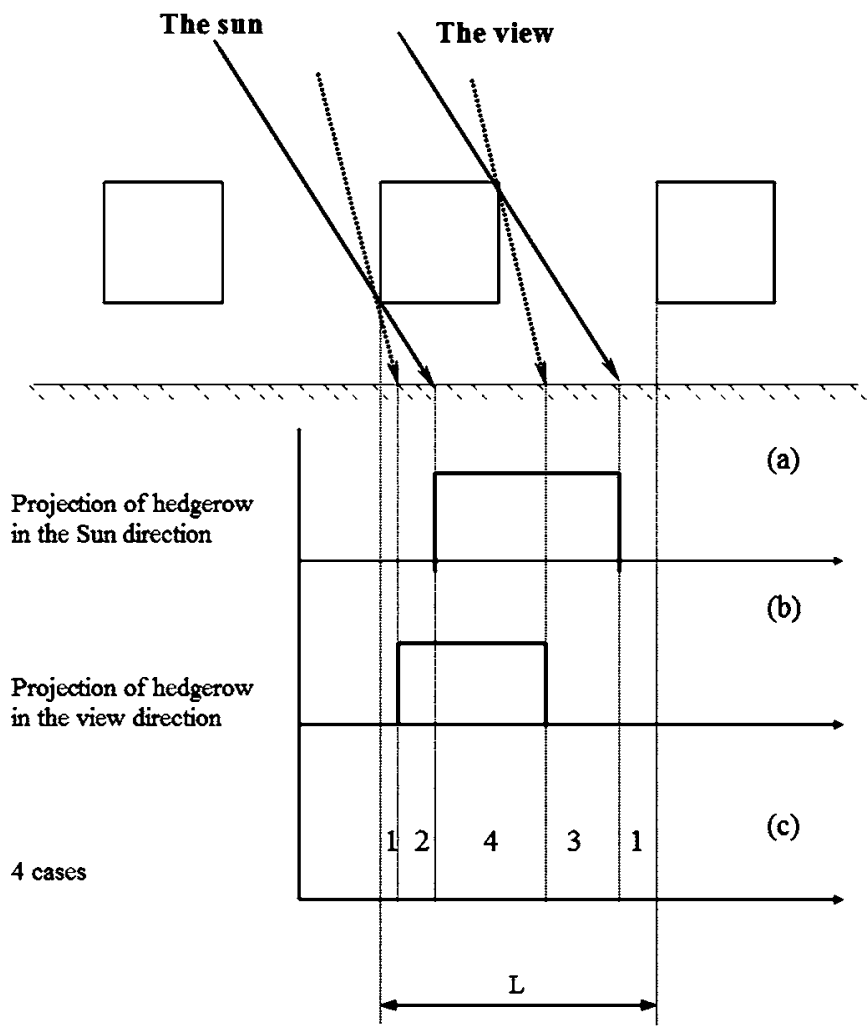

Fig. 3. Three components used in the model are computed by the combination of the vegetation projected on the soil plane along the sun and view direction.

TABLE I

GAP FRACTION AND THREE-COMPONENT FRACTIONS IN THE VIEW AND SUN DIRECTION

\begin{tabular}{ccccccc}
\hline & $G_{V}$ & $G_{S}$ & $H t$ & $C s b$ & $C s o$ & $C v$ \\
\hline$f_{l}$ & 1 & 1 & 1 & 1 & 0 & 0 \\
$f_{2}$ & $P_{2 V}$ & 1 & 1 & $P_{2 V}$ & 0 & $1-P_{2 V}$ \\
$f_{3}$ & 1 & $P_{3 S}$ & 1 & $P_{3 S}$ & $l-P_{3 S}$ & 0 \\
$f_{+}$ & $P_{+V}$ & $P_{4 S}$ & $H t$ & $P_{+l} P_{+S} H t$ & $P_{+V}\left(l-P_{+S} H t\right)$ & $1-P_{+V}$
\end{tabular}

TABLE II

INPUT PARAMETER VALUES FOR GORT MODEL

\begin{tabular}{ccccccccccc}
\hline $\begin{array}{c}\theta_{s} \\
\text { (degree) }\end{array}$ & $\begin{array}{c}\varphi_{s} \\
\text { (degree) }\end{array}$ & $\begin{array}{c}T_{s b} \\
\left({ }^{\circ} \mathrm{C}\right)\end{array}$ & $\begin{array}{c}T_{s o} \\
\left({ }^{\circ} \mathrm{C}\right)\end{array}$ & $\begin{array}{c}T_{v} \\
\left({ }^{\circ} \mathrm{C}\right)\end{array}$ & $\begin{array}{c}H \\
(\mathrm{~m})\end{array}$ & $\begin{array}{c}h \\
(\mathrm{~m})\end{array}$ & $\begin{array}{c}a \\
(\mathrm{~m})\end{array}$ & $\begin{array}{c}L \\
(\mathrm{~m})\end{array}$ & $\begin{array}{c}m \\
\left(\mathrm{~m}^{-1}\right)\end{array}$ & $L A I$ \\
\hline 30 & 30 & 45 & 33 & 27 & 1.4 & 0.3 & 0.6 & 1.0 & 5 & 2.5 \\
\hline
\end{tabular}

scales. The influence of leaf distribution and leaf angle distribution is represented by the dispersion coefficient $\lambda$ and projection function $G$, respectively. For maize canopies, Ross [31] showed the $\lambda$ varied from $0.5-1.8$, while Espana et al. [32] obtained $\lambda$ values varying from $0.5-1$ with an average value of 0.8 by using a numerical 3-D model. Campbell [33], [34] suggested an expression of $G$ as a function of the view zenith and the leaf angle distribution. The influence of the crown shape and plant position in field has been investigated by Jackson et al. [35], who modeled rows of orchards as opaque hedgerows with various cross sections. In many gap fraction studies [27], [36]-[38], the similar approaches were utilized to investigate the effect of the row structure and the leaf angle distribution on gap fraction for various hedgerow canopies (maize, cotton, olive, apple, etc.). In their studies, the vegetation rows were supposed porous, which could be penetrated by ray through the gaps within them. 
a

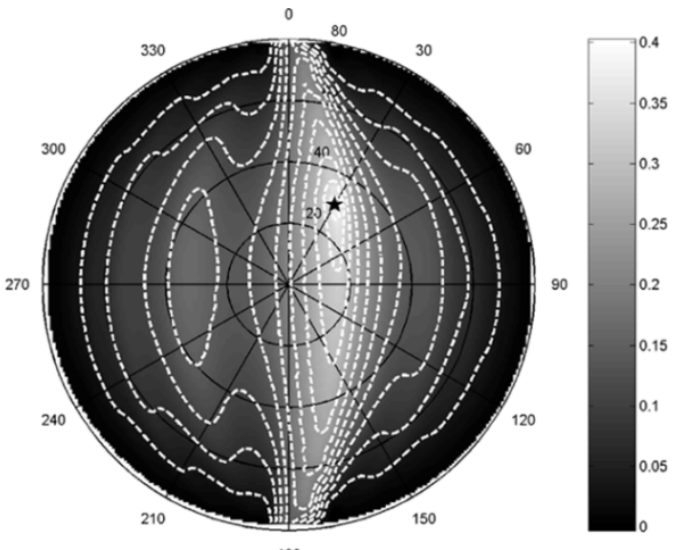

c

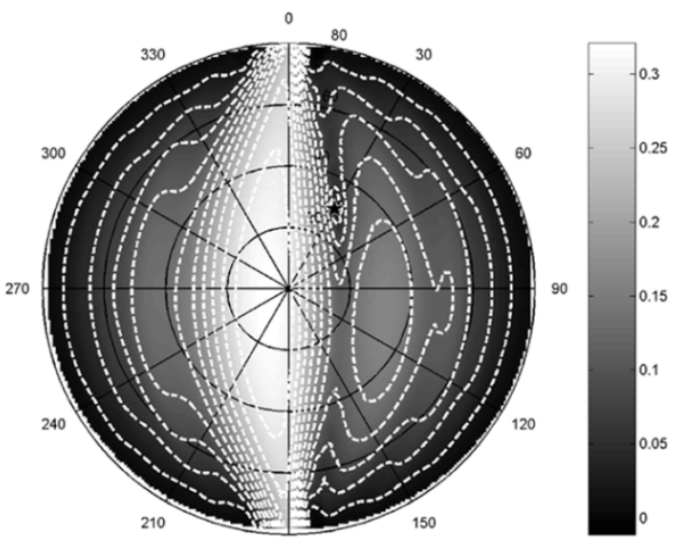

180

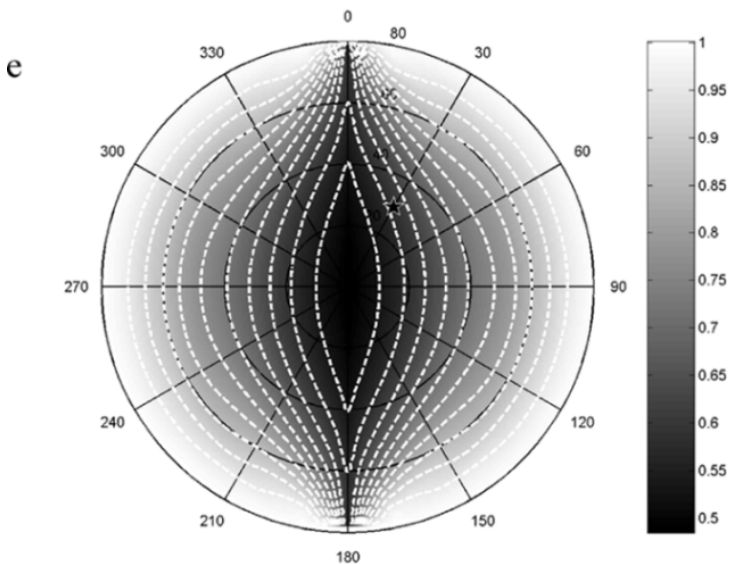

b
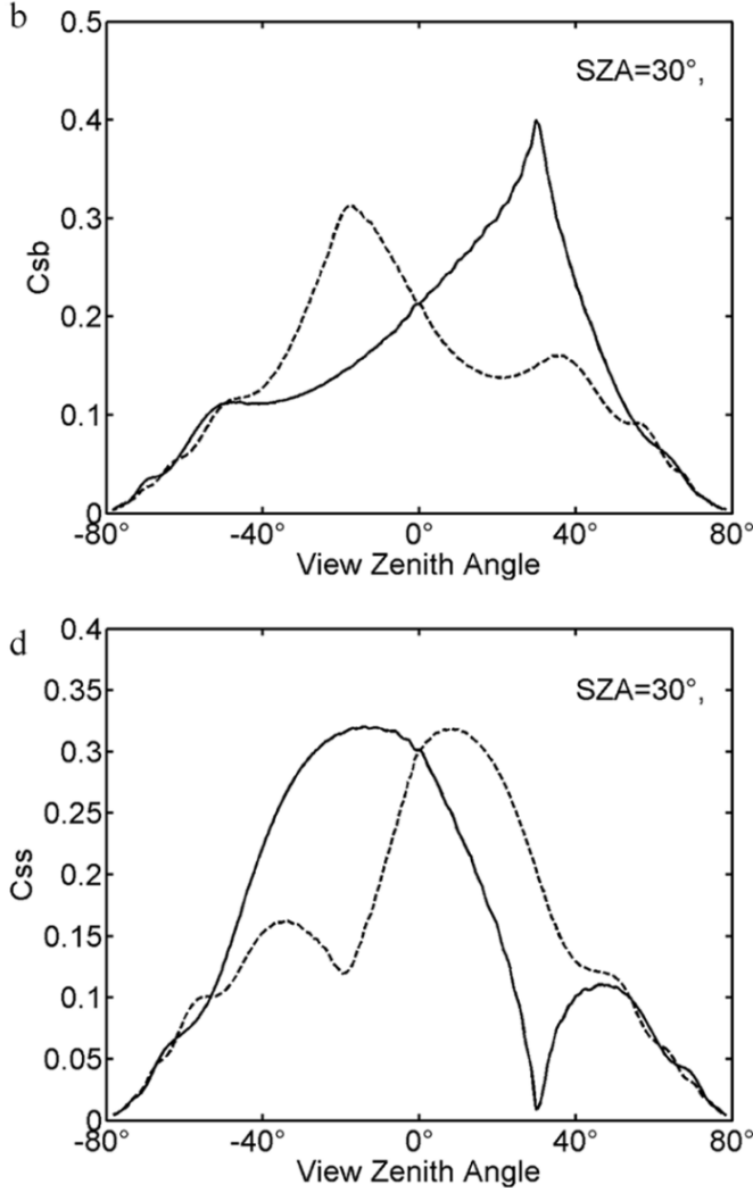

f

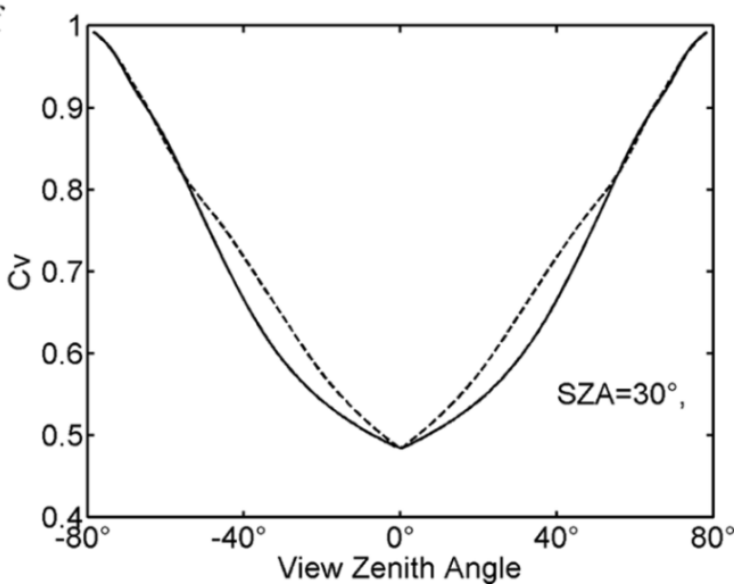

Fig. 4. Fractional distribution of three field types. (a) and (b) Sunlit soil. (c) and (d) Shaded soil. (e) and (f) Vegetation. In the left are the polar contour maps. In the right are the profiles in and across the sun principal plane.

Up to now, few simple physical models have been reported for studying row crop DBT considering the hot spot effect and row structure effect simultaneously. As mentioned above, the developed GO and GORT models considered only radiation interception between and within the plant rows. The objective here is to present a new GORT model, which could be applied to investigate the effect of the canopy geometrical structure and brightness temperature distributions on DBT variations. Gaps between and within the plant rows are calculated based on the recent results of gap fraction studies. Then, the directional frac- tions of brightness temperature components over the canopy are modeled.

\section{Modeling DBT of MaIZE CANOPY}

\section{A. Maize Canopy Geometrical Structure and} Sun-Target-Sensor Geometry

In models of Jackson et al. [2] and Kimes et al. [11], the maize canopy was treated as a number of opaque hedgerows standing on the soil plane. The soil lied between two adjacent hedgerows, 
a

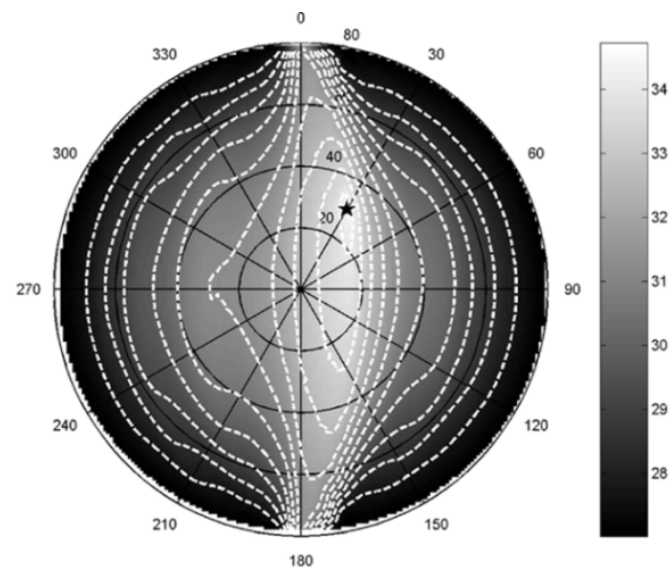

b

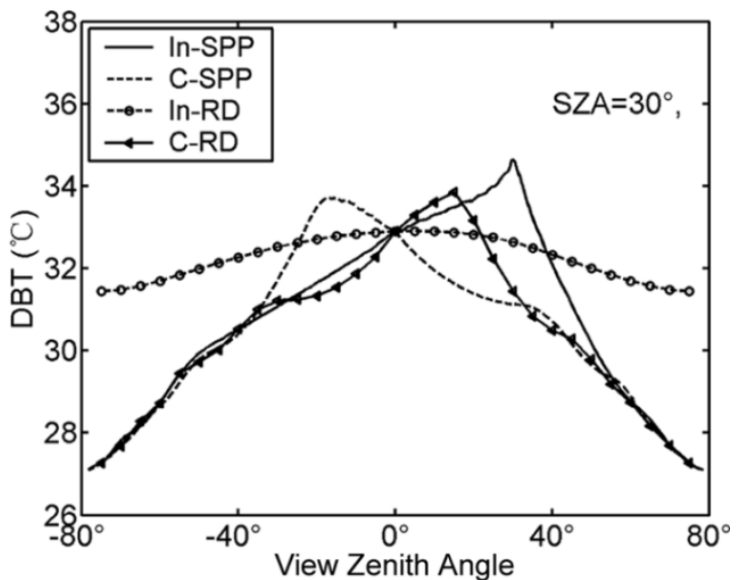

Fig. 5. Polar contour map (a) and profiles (b) of DBT variation. The figure shows four profiles in and crossing solar principal plane: In-SPP, C-SPP, In-RD, and C-RD.

a

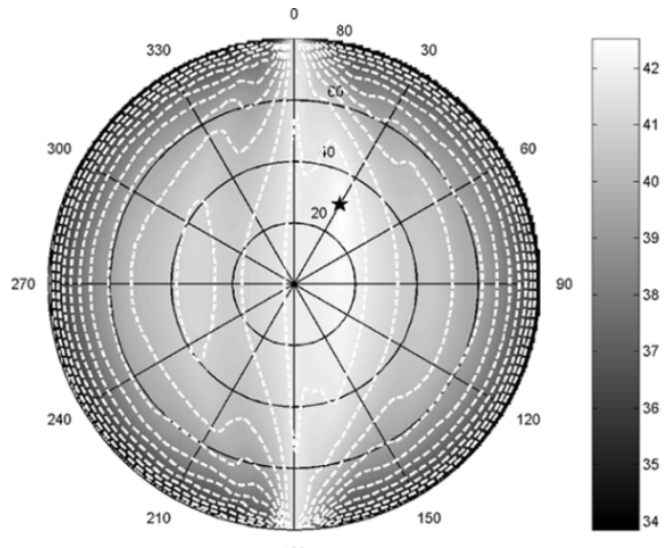

C

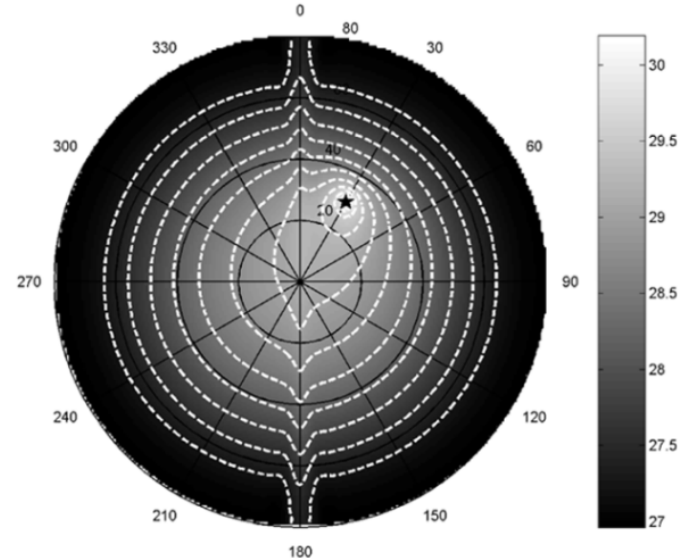

b

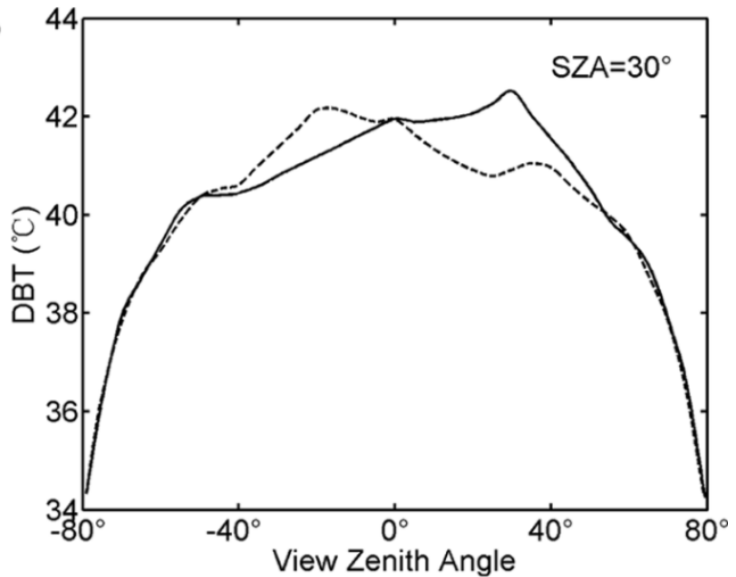

d

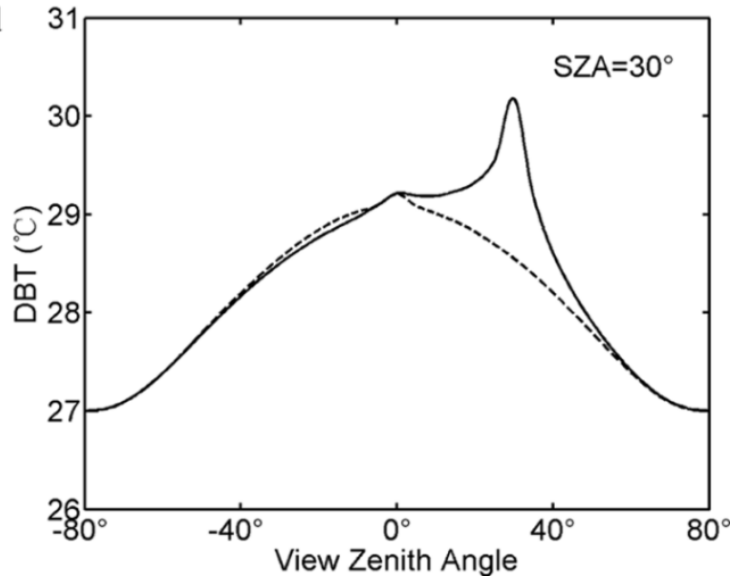

Fig. 6. Effect of hedgerow width on field DBT distributions. The ratio of hedgerow width to row distance is (a) and (b) 0.1 and (c) and (d) 0.95 , respectively.

and leaves were only distributed within the hedgerows. In this research, hedgerows are considered to be porous so that light beams could penetrate one or more rows through gaps within the hedgerows. Besides, the hedgerows are placed over the soil plane with a limit distance rather than directly on the soil surface [29]. Stems and small leaves between the soil plane and hedgerows are neglected. This simplification is acceptable in the case that most of the biomass concentrates in the upper part of plants. Fig. 1 shows the coordinate system and definition of variables as seen in the plane perpendicular to the row direction. The origin of $x$ is at the footprint of the left corner of one hedgerow; $H$ and $h$ are the heights of hedgerow upper and bottom edge, respectively; $b$ is defined as hedgerow thickness $(b=H-h)$; $a$ is hedgerow width; $L$ is row spacing. The sun and the view directions projected in perpendicular plane of rows are represented by their inclination angles $\alpha_{S}$ and $\alpha_{V}$, respectively. The absolute value of angle $\alpha$ is calculated as

$$
\tan \alpha=\tan \theta \sin \varphi
$$


a

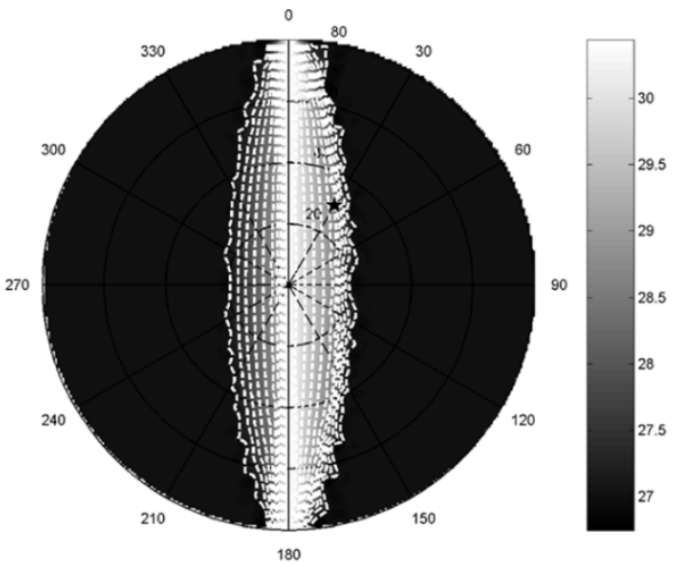

$\mathrm{c}$

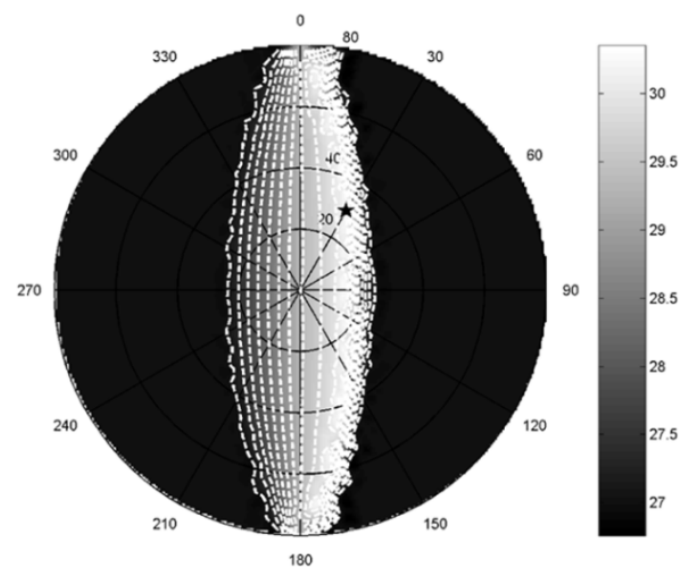

b

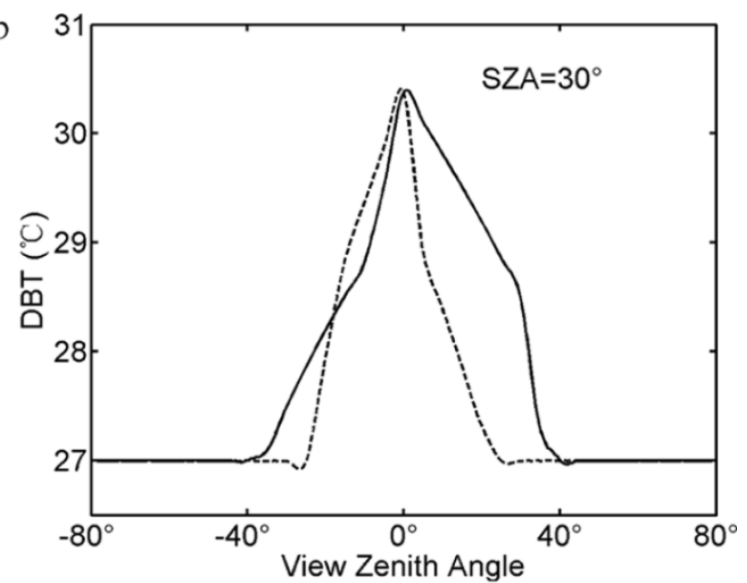

$\mathrm{d}$

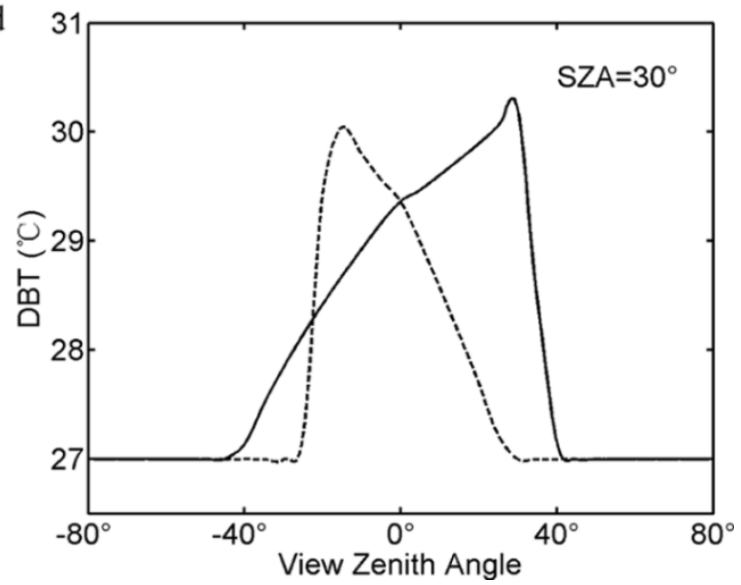

Fig. 7. Influence of hedgerow's bottom height on field DBT distributions. The ratio of distance to row distance is (a) and (b) 0 and (c) and (d) 0.5 , respectively.

where $\theta$ and $\varphi$ are the zenith and azimuth angle defining the sun or view direction. Since the symmetry feature of the canopy $\alpha_{S}$ is defined between $0^{\circ}$ and $90^{\circ}, \alpha_{V}$ is from $-90^{\circ}$ to $90^{\circ}$. If the view and the sun are in the same side of hedgerows, then $\alpha_{V}>0$; otherwise $\alpha_{V}<0$.

\section{B. Definition of the DBT and Three-Component Thermal Property of the Maize Canopy}

In ground measurement, the observed radiance emitted by an elementary at position $(x, y)$ within an infinitesimal range around wavelength $\lambda$ is [14], [39]

$$
\begin{aligned}
R_{\mathrm{B}, \lambda}(\theta, \varphi, x, y) & =R\left(T_{\mathrm{B}, \lambda}(\theta, \varphi, x, y)\right) \\
& =\varepsilon_{\mathrm{b}, \lambda} R\left(T_{\mathrm{b}, \lambda}(\theta, \varphi, x, y)\right)+L_{\lambda}^{\prime}(\theta, \varphi, x, y)
\end{aligned}
$$

where $R_{\mathrm{B}, \lambda}(\theta, \varphi, x, y)$ is the directional spectral radiance emitted and reflected by an element at position $(x, y)$. It is homogeneous and isothermal with a unique thermodynamic temperature. $T_{\mathrm{B}, \lambda}(\theta, \varphi, x, y)$ is the element directional brightness temperature derived from the radiance received by the detector, whose value equals to the blackbody temperature that gives the same power. $\varepsilon_{\mathrm{b}, \lambda}$ is the element surface spectral emissivity, a function of wavelength and position. $T_{\mathrm{b}, \lambda}(\theta, \varphi, x, y)$ is the element directional radiometric temperature derived from the radiance emitted by the element itself. $L_{\lambda}^{\prime}(\theta, \varphi, x, y)$ is the directional radiance due to the background contributors, e.g., the incident radiance from sky and other parts of the canopy.

Since the radiometer is far away from the target, the thermal radiance $R_{\mathrm{B}, i}(\theta, \varphi)$ received by the sensor in channel $i$ could be expressed by integrating the wavelength within the channel range $\left(\lambda_{1}, \lambda_{2}\right)$ and averaging the elemental radiance over the scene

$$
\begin{aligned}
R_{\mathrm{B}, i}(\theta, \varphi) & =R\left(T_{\mathrm{B}, i}(\theta, \varphi)\right) \\
& =\frac{\int_{S} \int_{\lambda_{1}}^{\lambda_{2}} R_{\mathrm{B}, \lambda}(\theta, \varphi, x, y) d \lambda d x d y}{\int_{S} d x d y} \\
& =\frac{\sum \Delta S \int_{\lambda_{1}}^{\lambda_{2}} R_{\mathrm{B}, \lambda}(\theta, \varphi, x, y) d \lambda}{S}
\end{aligned}
$$

where $T_{\mathrm{B}, i}(\theta, \varphi)$ is canopy directional brightness temperature, whose value equals to the temperature of a black body having the same radiance; $S$ is target's area size; $\Delta S$ is the size of the elemental area.

In this study, the elements having similar brightness temperature value and belonging to the same canopy component (soil 
a

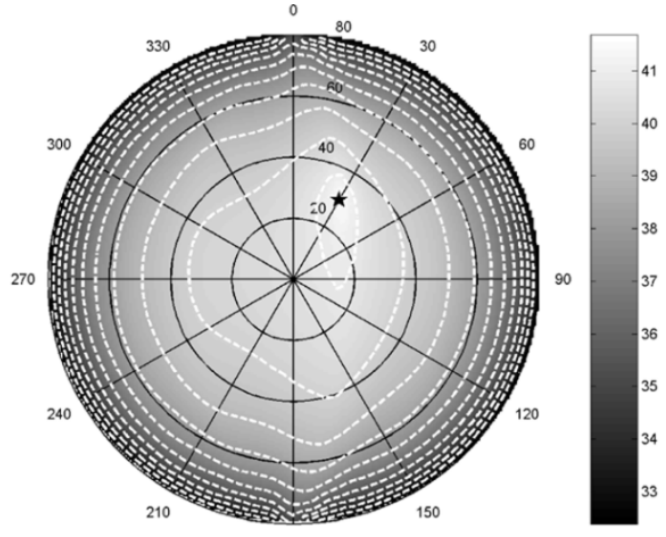

180
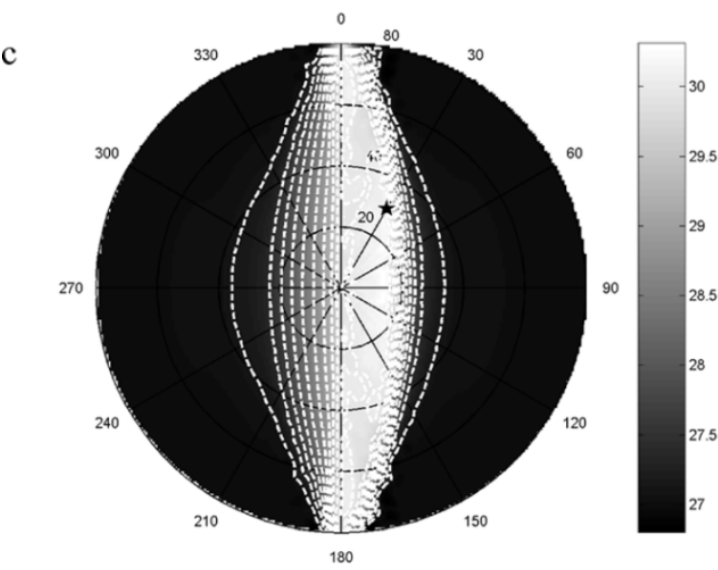

b

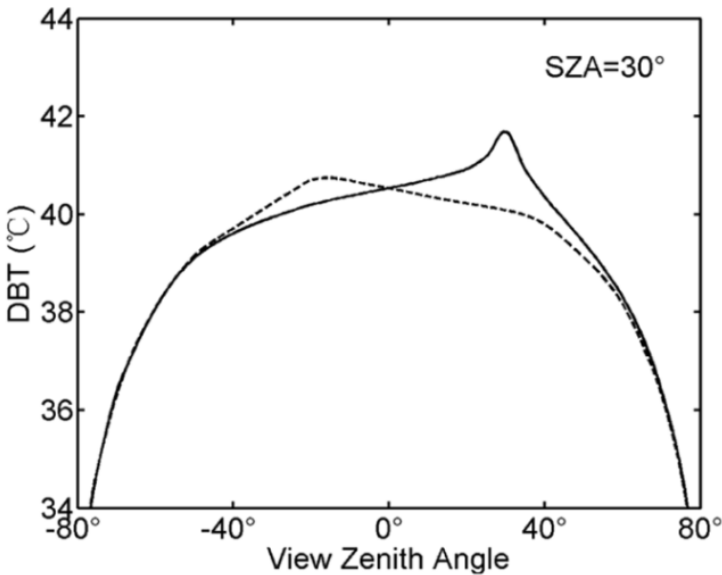

d

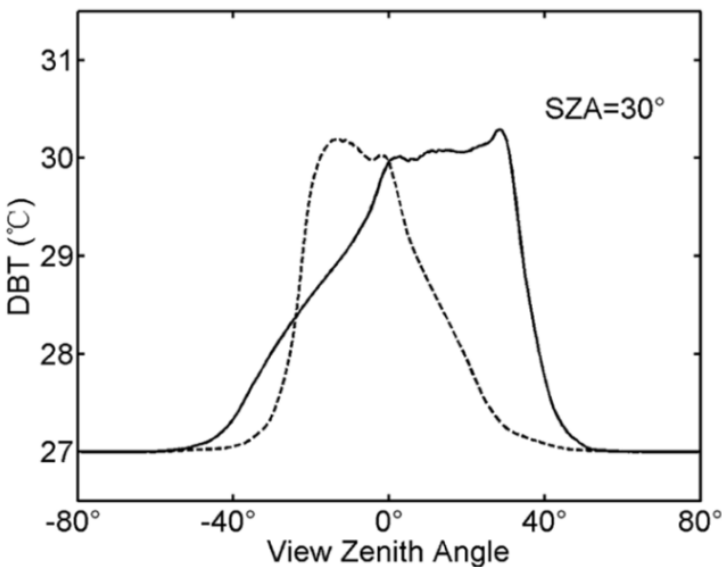

Fig. 8. Effect of canopy optical extinct property on field DBT distributions. The LAI values are (a) and (b) 0.3 and (c) and (d) 6, respectively.

or vegetation) are collected as one brightness temperature component, so the directional radiation could be expressed as a sum of component radiations

$$
\begin{aligned}
R\left(T_{\mathrm{B}, i}(\theta, \varphi)\right) & =\sum_{k=1}^{N} f_{k}(\theta, \varphi) R_{k, B, i}(\theta, \varphi) \\
& =\sum_{k=1}^{N} f_{k}(\theta, \varphi) R_{k, B, i}\left(T_{k}\right)
\end{aligned}
$$

where $N$ is the number of brightness temperature component, elements of each component have the same brightness temperature; $k$ represents the $k$ th group; $f_{k}(\theta, \varphi)$ is the relative area proportion of $k$ th group in the scene, whose value is normalized so the sum of $f_{k}(\theta, \varphi)$ is $1 ; R_{k, B, i}\left(T_{k}\right)$ is the component radiation; $T_{k}$ is the component brightness temperature of $k$ th group.

To simplify the calculation of $T_{\mathrm{B}, i}(\theta, \varphi)$ from $T_{k}$, the range of wavelength is expanded to the whole spectrum with the Stefan-Boltzmann law. For each brightness temperature component, the characteristic of the element thermal radiation is much similar. The radiance, as a function of wavelength for any elements of one component, is supposed to be the same. Then, (4) changes to be

$$
a_{\mathrm{B}} \sigma T_{\mathrm{B}}^{4}(\theta, \varphi)=\sum_{k=1}^{N} f_{k}(\theta, \varphi) a_{k} \sigma T_{k}^{4}
$$

where $T_{\mathrm{B}}(\theta, \varphi)$ is the target DBT; $a_{\mathrm{B}}$ is the ratio of the thermal radiation in channel $i$ to that in whole wavelength range of the target; $a_{k}$ is the ratio of the thermal radiation in channel $i$ to that in whole wavelength range for the component $k$; and $\sigma$ is the Stefan-Boltzmann constant.

To connect the directional brightness temperature $T_{\mathrm{B}}(\theta, \varphi)$ and the component brightness temperature $T_{k}$ directly, a simplification of (5) is conducted by ignoring the changes of $a\left(a_{\mathrm{B}}\right.$ and $a_{k}$ )

$$
T_{\mathrm{B}}^{4}(\theta, \varphi) \approx \sum_{k=1}^{N} f_{k}(\theta, \varphi) T_{k}^{4}
$$

The error caused by this process is inevitable because of the nonblackbody of the target. Olioso [40] shows that the ratio $a$ varies between $0.34-0.39$ for a blackbody whose temperature ranges from $-10{ }^{\circ} \mathrm{C}$ to $45^{\circ} \mathrm{C}$ in the wide thermal band of $8-14 \mu \mathrm{m}$. In clear days, if canopy component temperatures are between $20{ }^{\circ} \mathrm{C}$ and $50{ }^{\circ} \mathrm{C}$ during observations and the radiance from environment is small enough, the ratio $a$ varies between $0.37-0.39$ in the wide thermal band, which leads to the error of DBT calculations less than $0.5 \mathrm{~K}$. This is acceptable in this study compared with the range of canopy DBT variation. With a series of simplifications, the DBT has the same value as the directional composite temperature suggested by Kustas et al. [13], though their physics definitions are different. 
a

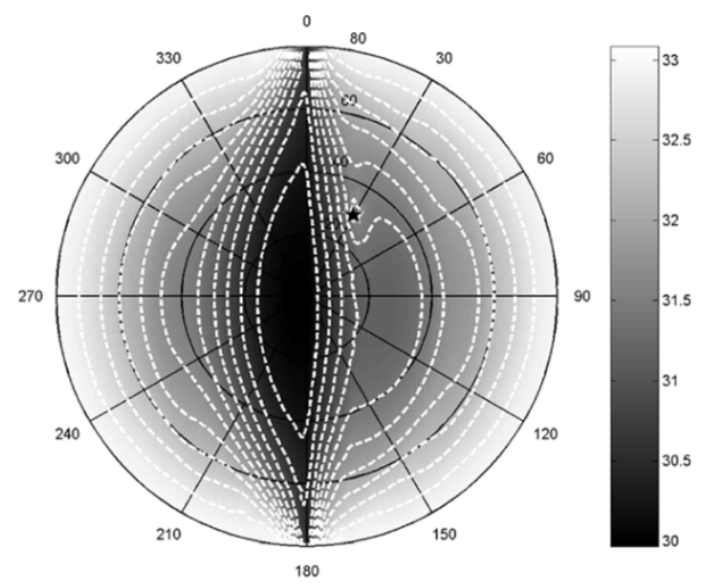

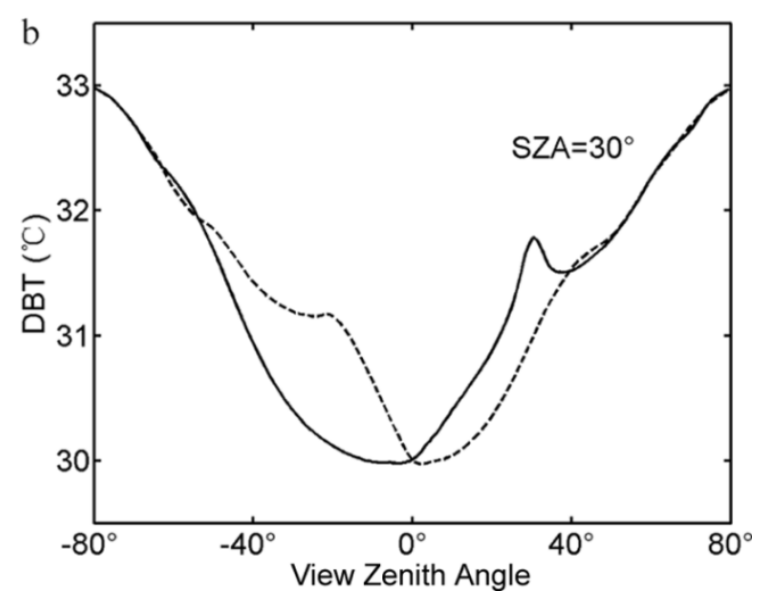

Fig. 9. Influence of component brightness temperature on the variations of DBT.

In this paper, the "three brightness temperature components" approach for canopy component classification is used referring to the research of Kustas et al. [13]. The vegetation is assumed to have a unique temperature, and the soil is divided into two parts according to the sunshine condition. So, these components are the sunlit soil, the shaded soil, and the vegetation. From experiments over row crops [2], [11], [13], researchers have reported that the temperature differences between the sunlit and the shaded vegetation are very small compared with the differences between the sunlit and the shaded soil. For example, Kimes et al. [11] reported a typical case in his measurement: the sunlit soil was $66.6^{\circ} \mathrm{C}$, the shaded soil was $44.3{ }^{\circ} \mathrm{C}$; the sunlit vegetation was $40.5^{\circ} \mathrm{C}$; and the shaded vegetation was $40.4^{\circ} \mathrm{C}$ : only $0.1{ }^{\circ} \mathrm{C}$ difference existed between the sunlit and the shaded vegetation. In our field experiments over the maize canopy, the assumption of three brightness temperature components has also been confirmed in daytime measurements over the whole growing period [41]. As a function of component brightness temperature multiplied by their respective fractional areas in the scenes, the DBT could be expressed as

$$
T_{\mathrm{b}}^{4}=T_{\mathrm{v}}^{4} C_{\mathrm{v}}+T_{\mathrm{sb}}^{4} C_{\mathrm{sb}}+T_{\mathrm{so}}^{4} C_{\mathrm{so}}
$$

where $T_{\mathrm{b}}$ is the DBT; $T_{\mathrm{v}}$ is the vegetation brightness temperature; $C_{\mathrm{v}}$ is the vegetation fraction; $T_{\mathrm{so}}$ is the shaded soil brightness temperature; $C_{\mathrm{so}}$ is the shaded soil fraction; $T_{\mathrm{sb}}$ is the sunlit soil brightness temperature; $C_{\mathrm{sb}}$ is the sunlit soil fraction.

\section{Gap Fraction of Maize Canopy}

Gap fraction relates to the field leaf area index (LAI) and the extinction parameter $k(\theta)$ for the homogeneous canopy [25]

$$
P(\theta)=e^{-k(\theta) \mathrm{LAI}}
$$

where $k(\theta)$ depends on the observation direction, the canopy density distribution, and the canopy architecture such as the leaf inclination and clumping level [24], [28], [29]

$$
k(\theta)=\frac{\lambda(\theta) G(\theta)}{\cos \theta}
$$

where $\theta$ is the view zenith; $G(\theta)$, the projection function, is the projection of a unit leaf area onto the surface normal to the direction of observation; $\lambda(\theta)$ is the leaf dispersion coefficient, also called "clumping parameter," which reflects an influence of leaf spatial distribution on the gap fraction.

Li et al. [28] expanded the model to the discontinuous canopy by considering crown gaps as a function of path length

$$
P(\theta, \varphi, x, y)=\exp (-\tau l(\theta, \varphi, x, y))
$$

where $l(\theta, \varphi, x, y)$ is the effective path length that only accounts for the beam passing through the canopy, while the length passing through the adjacent space among the rows is neglected. Here, $\tau(\theta)$ is defined as the attenuation coefficient in a form of $\tau(\theta)=\lambda(\theta) G(\theta) D$, where $D$ is the effective leaf area density with a unit of square meters per cubic meter, equaling $(\mathrm{LAI} \times L) / a b$.

According to those studies of Campbell [33], [34] and Espana et al. [35], $\lambda(\theta) G(\theta)$ is a function of maize phenological stage and view direction (Fig. 2). In the simulation, its value is calculated in interoperation approach based on the curves corresponding to different LAI value.

The canopy gap fraction $P(\theta, \varphi)$ is obtained by integrating element values over the whole area $S$

$$
P(\theta, \varphi)=\frac{\iint_{S} P(\theta, \varphi, x, y) d x d y}{S} .
$$

Considering the periodicity of the canopy row structure, the expression of gap fraction is simplified. $l(\theta, \varphi, x, y)$ changes periodically along the $x$ axis and remains constant along the $y$ axis, so we only observe the gap fraction within a row space $L$ along the $x$ axis. Therefore, $P(\theta, \varphi, x)$ is expressed as

$$
P(\theta, \varphi)=\frac{\int_{L} P(\theta, \varphi, x) d x}{L} .
$$

\section{Bidirectional Gap Fraction}

An exponential model developed by Kuusk [42] for homogeneous canopy is applied that the fraction of sunlit soil in the scene is [43]

$$
\begin{aligned}
P & =P_{\mathrm{s}} P_{\mathrm{v}} H t \\
& =\exp \left(-\tau\left(l_{\mathrm{s}}+l_{\mathrm{v}}-\frac{1-\exp \left(-m l_{\mathrm{sv}}\right)}{m l_{\mathrm{sv}}} \sqrt{l_{\mathrm{s}} l_{\mathrm{v}}}\right)\right)
\end{aligned}
$$


where $P_{\mathrm{s}}$ is the gap fraction in the sun direction, $P_{\mathrm{v}}$ is the gap fraction in the view direction, $H t$ is the bidirectional function, $\tau$ is the attenuation parameter, three values of $\tau\left(\theta_{\mathrm{S}}\right), \tau\left(\theta_{\mathrm{v}}\right)$, and $\tau\left(\theta_{\mathrm{s}}, \theta_{\mathrm{v}}\right)$ are used corresponding to $P_{\mathrm{s}}, P_{\mathrm{v}}$, and $H t$, respectively; $l_{\mathrm{S}}$ and $l_{\mathrm{v}}$ are the within-hedgerow path lengths of the sunlight and sunview, respectively; $m=1 / s, s$ is the characteristic linear dimension of foliage elements; $l_{\mathrm{sv}}$ is the difference between incident and viewing path length

$$
l_{\mathrm{sv}}=\left|\vec{l}_{\mathrm{v}}-\vec{l}_{\mathrm{s}}\right|=\sqrt{l_{\mathrm{v}}^{2}+l_{\mathrm{s}}^{2}-2 l_{\mathrm{v}} l_{\mathrm{s}} \cos \xi}
$$

where $\cos \xi$ is the scattering angle, which could be derived from the zenith and azimuth of sunlight and sunview

$$
\cos \xi=\cos \theta_{\mathrm{s}} \cos \theta_{\mathrm{v}}+\sin \theta_{\mathrm{s}} \sin \theta_{\mathrm{v}} \cos \left(\varphi_{\mathrm{v}}-\varphi_{\mathrm{s}}\right)
$$

where $\theta_{\mathrm{s}}, \theta_{\mathrm{v}}, \varphi_{\mathrm{s}}$, and $\varphi_{\mathrm{v}}$ are zenith and azimuth of incident light and view, respectively.

\section{E. Determination of Three-Component Fractions in Scene}

Three-component fractions could be evaluated by combing the projections of a hedgerow in sun and view directions over the soil plane. Fig. 3 shows projections along the sun and viewing directions, respectively, as seen in the plane perpendicular to the row direction. Due to periodic structure of the row canopy, the component distribution within one row space is analyzed.

Fig. 3(a) and (b) presents the hedgerow projections along the sun and the viewing directions by rectangle flags. If $\alpha_{S}$ is not zero and the viewing direction is not along the sunlight, the combination of these two flags gives the maximum of four cases in the $x$ axis on the soil plane [Fig. 3(c)].

- Case 1 shows that the sunlit soil is viewed directly by the observer. Neither the sunlight nor the view is obscured by the hedgerow. The fraction of this case is noted as $f_{1}$. Obviously, if inclination angle of solar radiation or view is large enough, soil plane will be obscured by the hedgerow, and this part will diminish or disappear.

- Case 2 is the sunlit soil viewed by passing through hedgerow. In this case, two components can be observed: the vegetation and the sunlit soil. The fraction of the sunlit soil is the gap fraction of the vegetation in the viewing direction $P_{2 V}$. The vegetation fraction is then $1-P_{2 V}$. The fraction of this case is noted as $f_{2}$.

- Case 3 relates to the situation in which part of the sunlight is intercepted by the hedgerow. However, the observer views the motley soil unobstructed by the hedgerow. In this case, only two components can be observed: the sunlit and shaded soil. The fraction of the sunlit soil is the gap fraction along the sun direction $P_{3 S}$, and the fraction of shaded soil is then $1-P_{3 S}$. The fraction of this case is noted as $f_{3}$.

- In case 4, both the view and solar beam pass through the hedgerow. All three components are observed in the scene. The fraction of vegetation is $1-P_{4 V}$; the fraction of the sunlit soil is $P_{4 V} P_{4 S} H t$; and the fraction of shaded soil is $P_{4 V}\left(1-P_{4 S} H t\right) . P_{4 V}$ and $P_{4 S}$ are gap fractions for view and sun beam directions, respectively, and $H t$ is the corresponding bidirectional function. The fraction of this case is noted as $f_{4}$.
Table I summarizes three-component fractions in four cases. Finally, we obtain the fractions of three components (the sunlit soil, the shaded soil, and the vegetation) as

$$
\begin{aligned}
C s b & =f_{1}+f_{2} P_{2 V}+f_{3} P_{3 S}+f_{4} P_{4 V} P_{4 S} H t \\
C s o & =f_{3}\left(1-P_{3 S}\right)+f_{4} P_{4 V}\left(1-P_{4 S} H t\right) \\
C v & =f_{2}\left(1-P_{2 V}\right)+f_{4}\left(1-P_{4 V}\right) .
\end{aligned}
$$

In other conditions that the number of the cases appeared is less than four or their positions change, the same analysis could also be applied. In the simulation, since the gap fraction and the bidirectional function depend on spatial positions, a numerical integration is used to compute the component fractions.

\section{Model RESULtS}

In the model, the canopy geometric structure has been simplified as a number of hedgerows with rectangle section in the cross direction. The interception of leaves is characterized by the attenuation parameter as a function of LAI. Scenes of view are classified into three components whose fractions depend on the geometrical parameters and the sun-view geometry. Therefore, the input parameters for the model are grouped as follows:

1) sun and view directions (zeniths and azimuths as $\theta_{\mathrm{S}}, \theta_{\mathrm{v}}$, $\left.\varphi_{\mathrm{s}}, \varphi_{\mathrm{v}}\right)$

2) canopy geometry parameters: row distance $L$; hedgerow height and its bottom height $H$ and $h$; hedgerow width $a$; dimension of foliage elements $m$; biomass density LAI; and row direction;

3) brightness temperature of sunlit soil, shaded soil, and vegetation: $T s b, T s o$, and $T v$.

Table II shows the value of input parameters for the simulation.

\section{A. Variation of DBT and the Fractions of Three Brightness Temperature Components}

Directional distribution of three component fractions is shown in Fig. 4: the sunlit soil [Fig. 4(a) and (b)], the shaded soil [Fig. 4(c) and (d)], and the vegetation [Fig. 4(e) and (f)], with 3-D polar-contour maps on the left and profiles in solar principal plane (solid line) and cross the solar principal plane (dash line) on the right. The solar zenith angle (SZA) is assumed positive. The profiles in solar principal plane start in the direction $80^{\circ} / 30^{\circ}$ (zenith/azimuth) and end in the direction $80^{\circ} / 210^{\circ}$. The profiles crossing the solar principal plane start in the direction $80^{\circ} / 300^{\circ}$ and end in the direction $80^{\circ} / 120^{\circ}$. In polar maps, the solar position is marked as a star in the direction $30^{\circ} / 30^{\circ}$, and the row direction is along the azimuth angle $0^{\circ}$ and $180^{\circ}$.

In Fig. 4(a), the sunlit soil fraction reaches its maximum in the sun direction. Its value decreases slowly along or near the row direction even at a large view inclination, which results in a stripe of high value in the map. In other azimuths, the sunlit soil fraction decreases sharply and turns to zero with the increase of zenith angles. The maximum value is shown as a peak at the sun position in the profile along the solar principal plane [Fig. 4(b)]. With the change of view zenith angle, the value decreases monotonously. Contrary to the distribution of the sunlit soil fraction, large values of shaded soil fractions appear in the solar forward direction [Fig. 4(c)]. The minimum 
value is at the sun position. This feature is also presented by the profiles in Fig. 4(d) that a quick drop appears in the sun direction along the sun principal plane, whose value turns to zero. Along the row direction in the polar map, the shaded soil keeps a high fraction value even in large zenith view, which is similar to the distribution of the sunlit soil. A symmetry feature appears in the polar-contour map for vegetation fractions [Fig. 4(e)]. Low values of vegetation fractions concentrate along the row direction, and the minimum value appears in the nadir because the largest gap fraction appears in the direction. With the increase of viewing zenith, the vegetation fraction increases steadily for all azimuths except for the row direction. The above patterns of three components explain the interaction of the sunlight and vegetation 3-D structure well. The symmetry of the vegetation fractions in the polar map disappears in maps for the sunlit and shaded soil. In the sun direction, only the sunlit soil could be seen; the sunlit soil fraction is at a peak value. and the shaded soil fraction becomes zero. Along the row direction including the nadir, most of the soil is observable. The fractions of the sunlit and shaded soil keep at high values. Thus, most high values of the sunlit soil fraction concentrate in the sun backward direction, and most high values of the shaded soil fraction concentrate in the sun forward direction. They are all along the row direction.

The corresponding DBT was calculated. Fig. 5(a) and (b) shows, respectively, the polar-contour map and four profiles along different directions: In-SPP (in solar principal plane), C-SPP (crossing solar principal plane), In-RD (in row direction), and C-RD (crossing row direction). In-RD is from $80^{\circ} / 90^{\circ}$ (zenith/azimuth) to $80^{\circ} / 270^{\circ}$; C-RD is from $80^{\circ} / 0^{\circ}$ to $80^{\circ} / 180^{\circ}$. In Fig. 5(a), a high value of DBT is around the sun direction and along the row direction. We can observe a hot stripe in the row direction and a hot spot in the sun direction. This hot spot is a long narrow stripe parallel to the row direction in the polar map. The feature of DBT depends on canopy component directional distributions. More soil could be seen along the row direction. Specially, in the sun direction, all the observable soil is illuminated, which leads to a hot spot. Therefore, similar to directional distributions of the sunlit soil fraction, high temperature values are located along the row direction even in large inclination view. In the backward direction, the DBT peak appears and in the forward direction, the temperature declines more sharply than the DBT between the nadir and the sun direction. In the profile map, the difference of temperatures between the hot spot and the nadir is only about $2{ }^{\circ} \mathrm{C}$, while the DBT range is $8{ }^{\circ} \mathrm{C}$, from $27^{\circ} \mathrm{C}$ to $35^{\circ} \mathrm{C}$. A turn point appears in the nadir for two profiles. This is due to the row structure of the canopy because most of the sunlit soil is obscured when we observe the canopy in the forward direction of the sun.

\section{B. Sensitivity Analysis of Key Input Parameters}

The advances of this GORT model lie: 1) in its simplification of geometric structure of a row canopy and 2) three brightness temperature component concepts. In this section, we will evaluate the sensitivity and the stability of the model to five key input parameters: the hedgerow width, the bottom height, the biomass density, the component brightness temperatures, and the sun positions.
Effect of Hedgerow Width a: Hedgerow width determines the gap distributions within the canopy. For a narrow row canopy, gaps are mainly concentrated among the hedgerows; otherwise, gaps may be mainly within the hedgerows for a wide hedgerow canopy. Fig. 6 illustrates the influence of the hedgerow width on the DBT by giving two extreme values, with the 0.1 [Fig. 6(a) and (b)] and 0.95 [Fig. 6(c) and (d)] as the inputs. Other input parameters are the same as those presented in Table I. The hot stripe only appeared in the first case. With a small hedgerow width, the hot stripe is widened and elongated. The temperatures of this string including the hot spot have the similar value. Only at a large zenith view, the DBT decreases quickly due to the increase of vegetation fractions. For very wide hedgerows or nearly fully covered conditions, the row effect disappears in the polar map, and the hot spot retreats to be a sharp peak. Its temperature is much higher than that of other directions. The row effect on the DBT is greatly declined. From these two simulations, a fully covered canopy has a sharper hot spot peak, and a narrow row canopy has a smaller hot spot peak compared with the canopy with a proper hedgerow width (Fig. 5).

Effect of Hedgerow's Bottom Height h: In order to show the influence of the hedgerow bottom height, the simulated DBT with different $h$ values presents in Fig. 7. In the simulation, the values of $h$ are supposed to be 0 [Fig. 7(a) and (b)] and 0.5 [Fig. 7(c) and (d)]; the hedgerows are assumed to be opaque; and the other input parameters are the same as those presented in Table I. In Fig. 7(a), the maximum temperature is observed in the nadir. When the bottom of the hedgerow touches the soil plane, both the sunlit and shaded soil will only be observed in the nadir or along the row direction, and the vegetation fraction is minimized, which leads to a maximum value of DBT. When the bottom height $h$ is not zero, part of the soil under the hedgerow is illuminated and is observable in the backward direction. If $h$ is large enough [Fig. 7(c) and (d)] that more soil right under the hedgerow is illuminated, a hot arc within the hot stripe appears, which lasts from $80^{\circ} / 0^{\circ}$ to $80^{\circ} / 180^{\circ}$ throughout the polar map. The arc is right through the solar position and at the edge of the hot stripe. All the sunlit soil could be seen along the arc, which leads to a high temperature value. It is obvious when $h$ is fairly small. The DBT in solar direction is not always greater than that of the nadir because the vegetation fraction for the view along the sunlight is larger than that in the nadir. In the cases that the soil is warmer than the vegetation, the position of the maximum temperature might appear between the sun direction and the nadir due to the hedgerow bottom height. In this discussion, the hot spot effect of row crops comes not only from the bidirectional gap fractions but also from the crown shape and the position of hedgerows. There may exist a temperature peak in sunlit direction, but the position of the maximum DBT will be in or near the sun direction depending on the component brightness temperatures.

Effect of Canopy LAI: As described earlier, the LAI and canopy geometrical parameters determine the interception capacity of the canopy by the attenuation parameter. Fig. 8 shows the DBT for two LAI values, 0.3 and 6, corresponding to the initial and maximum leaf development stages of maize canopy. All the other input parameters are the same as those in the Table I. 
Fig. 8(a) shows that a low LAI produces a large hot region with a declined hot spot. The temperatures of this region have the similar values. The row structure and hot spot effects are very small. If the LAI is very large, the hedgerows become opaque, and the hot stripe gets more evident in the polar map [Fig. 8(c)]. However, with a large LAI, a narrow peak of hot spot appears. Its range is minimized, which is different from that of Fig. 6(b). This is due to the decrease of the gaps for a denser canopy in which less soil is sunlit and observed.

For comparison, Fig. 5 represents a case for an intermediate biomass density with a LAI of 2.5. The directional variation is more obvious compared to the two extreme LAI cases. For a very sparse canopy (LAI $=0.3$ ), the $\mathrm{DBT}$ is mainly dominated by soil components. The mean DBT is very high and has little variation within a large zenith ranges. On the contrary, for a LAI equaling to 6 in a very dense condition, the feature of the DBT is dominated by hedgerow shapes and vegetation temperature, which leads to a low mean temperature, a small hot spot, and a clear stripe structure in the polar map. Note that the maximum DBT range may appear with proper LAI values instead of extreme conditions.

Effect of Brightness Temperature Components: Component brightness temperatures and their value orders vary with measuring time and date. The influence of component brightness temperatures on the DBT distribution generates a new temperature order. The results are presented in Fig. 9. In the simulation, the brightness temperature of the sunlit soil, the shaded soil, and the vegetation are changed to be $30^{\circ} \mathrm{C}, 25^{\circ} \mathrm{C}$, and $33^{\circ} \mathrm{C}$, with other geostructure parameters the same as those in Table I. Contrary to the polar maps and profiles shown earlier, the minimum temperature appears in the nadir view; the DBT has a bowl shape similar to that of vegetation directional fraction except for a hot spot in the sun direction. The inversion of the curve is due to the inversion of the order of the component temperature. This inversion exists in many situations: a very high vegetation density, high soil moisture resulting from irrigation, or the time between the midnight and early morning. This evolution demonstrates that component brightness temperatures play an important role in the characteristics of the canopy DBT.

Effect of the Sun Position: To investigate the effect of sun position on the variation of row crop DBT, three sun positions are used in the simulation (Fig. 10). Solar zeniths were

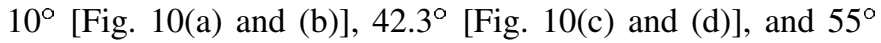
[Fig. 10(e) and (f)], respectively, with a constant azimuth angle of $30^{\circ}$; other parameters remain the same as those in Table I. When the solar zenith is small [Fig. 10(a) and (b)], the hot spot and the hot stripe are narrow, and the hot spot locates within the hot stripe. When the solar zenith increases to $42.3^{\circ}$, sunlight could not reach the soil directly. The hot stripe is widened, and the hot spot becomes to be a hot region and locate at the edge of the hot stripe. When the zenith of the sun continues to increase, the hot stripe and the hot spot become separate [Fig. 10(e) and (f)], and the maximum temperature appears at the nadir.

The hot spot and the row structure are two important features in the simulation of the DBT. The solar position decides whether these two effects are overlapped or separated and where the maximum DBT appears. When the sunlight could reach the soil without penetrating hedgerows, the peak value of the DBT may appear in the solar direction. Otherwise, the peak value ap- pears in the nadir direction or between the nadir and solar direction according to the component temperature and component fractions in the view. This phenomenon was also mentioned by Lagouarde et al. [14]. In their experiment over a maize canopy, the maximum value was not in the sunlight direction. As analysis, the maximum value of the DBT is in the sun direction only when the sun zenith is within the range of $0^{\circ}$ to $42.3^{\circ}$.

\section{VALIDATION AND DISCUSSION}

\section{A. Experimental Data Used for Model Validation}

To validate the model, the simulated results are compared with the measured DBT acquired in 1999. The experimental field is located at the Institut National de la Recherche Agronomique at Avignon, southern France $\left(43^{\circ} 57^{\prime} \mathrm{N}\right.$ latitude, $4^{\circ} 5^{\prime} \mathrm{E}$ longitude). The maize was planted north-south oriented on May 10, 1999. The row space was $0.8 \mathrm{~m}$, and plant density was 9.32 plants $/ \mathrm{m}^{2}$. Experiments were conducted several times from June 4 to August 6, with a change of LAI from 0.05 to 5.3 , covering nearly the entire period of maize canopy growth.

The dataset of the DBT was extracted from thermal images acquired by a thermal camera INFRAMETRICS Model 760 [10]. The camera was equipped with a $71^{\circ} \times 55^{\circ}$ wide lens, and the spectral window was from 7.25-13.25 $\mu \mathrm{m}$. During the measurement, the camera was mounted on the beam of an industry crane, with the cameras $20 \mathrm{~m}$ above the ground.

\section{B. Comparison and Discussion}

A measurement was conducted at $13 \mathrm{~h} 10$ of local time on June 24, 1999. The obtained maize DBT is shown in Fig. 11. Fig. 11(a) is the polar contour map of the DBT, and Fig. 11(b) is four profiles in and across the solar principal plane and row direction. In the polar map, the north direction is assumed to be the origin with an azimuth angle of $0^{\circ}$. The azimuth of the south, the east, and the west are $180^{\circ}, 90^{\circ}$, and $270^{\circ}$, respectively. In Fig. 11(a), a wide hot stripe appeared along the row direction. The middle part of the stripe is the widest, and the two poles are the narrowest. The sun position is within the strip and among the hottest part, which is located between solar position and the axis of azimuth $270^{\circ}$. However, there is not a hottest peak in the sun direction as expected. As analysis, the camera's shadow might disturb the forming of the hot spot peak in the direction of solar light. In the figure, there are some flaws, of which the plot surface is not as smooth as expected, and there are some strange values. We attribute these to the heterogeneity of canopy radiance and measurement errors inevitable completely. Besides, the interpolation process produced errors at two ends of the hot stripe. These errors need to be removed in the further analysis.

Fig. 11(b) shows four DBT profiles in and across the solar principal plane. Profiles of In-SPP and C-SPP have a similar shape and inverse symmetry between each other. The highest temperature appears in the hot spot direction and the profile C-RD. The temperature decreases rapidly in solar backscatter direction but slowly in the solar forward scattering direction. The temperature difference between the hot spot direction and the nadir is only $1.5^{\circ} \mathrm{C}$, and the whole range of temperature difference is $7^{\circ} \mathrm{C}$. 
a

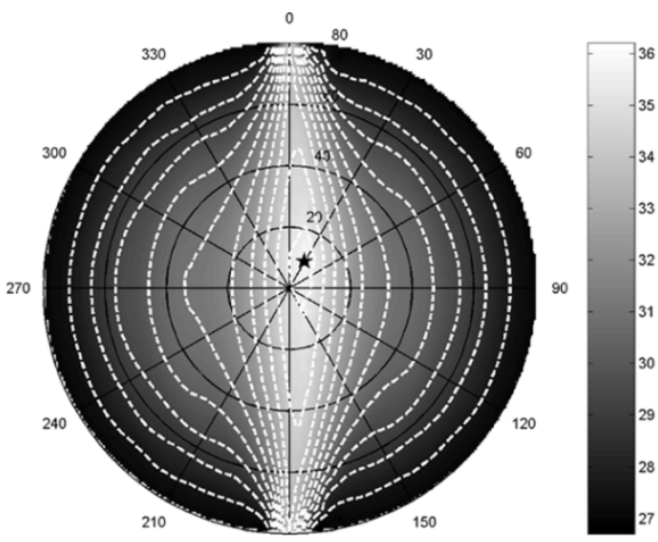

$\mathrm{c}$

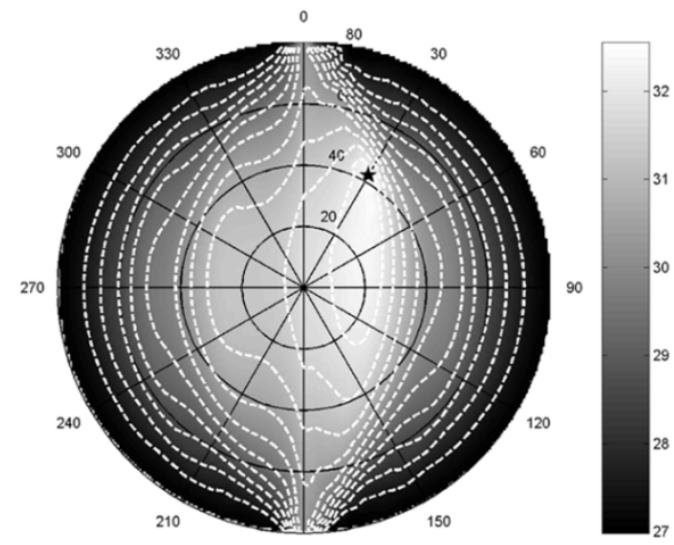

180

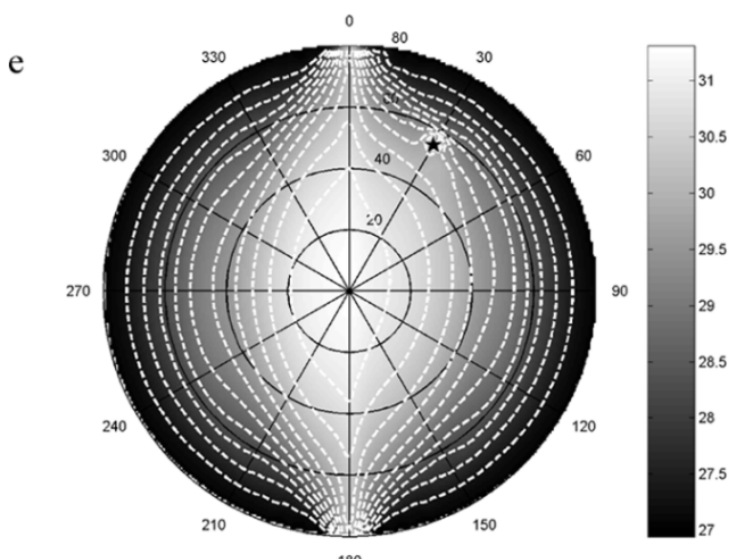

b

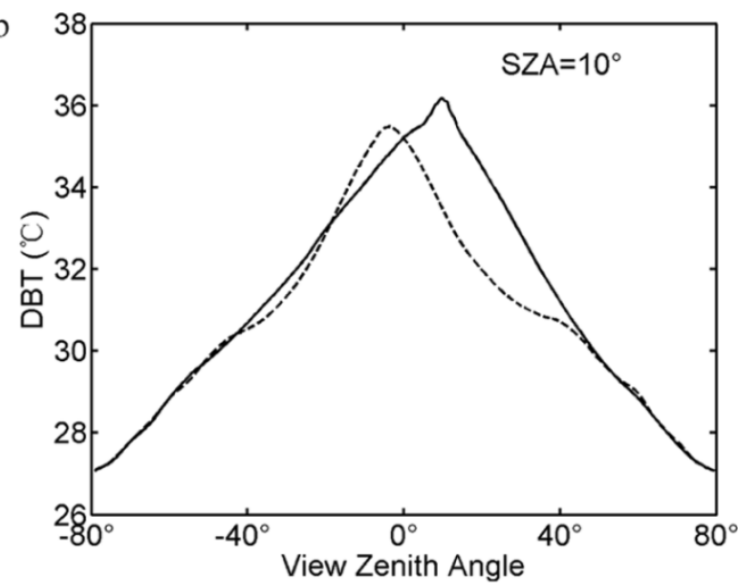

d
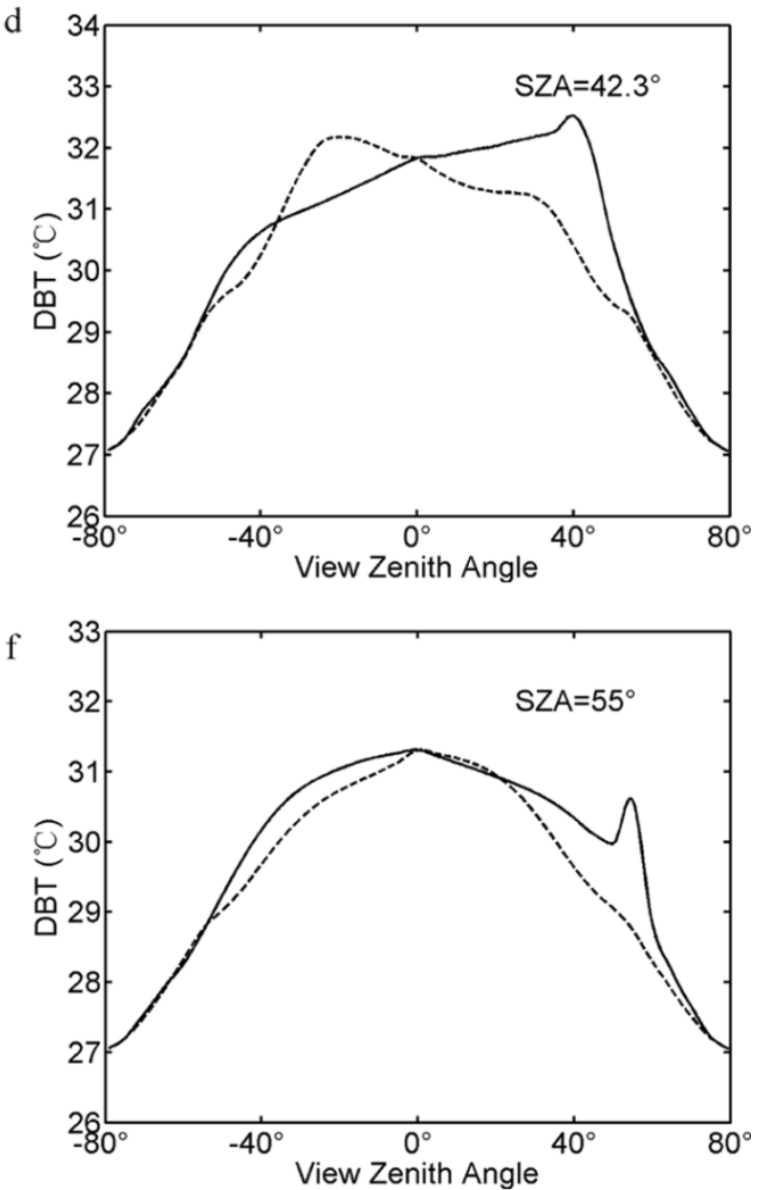

Fig. 10. Influence of solar position on DBT variations. The zenith and azimuth at different time are (a) and (b) $10^{\circ} / 30^{\circ}$, (c) and (d) $42.3^{\circ} / 30^{\circ}$, and (e) and (f) $55^{\circ} / 30^{\circ}$, respectively.

A DBT from the model is shown in Fig. 12(a) and (b), respecitvely: a polar-contour map of DBT with a zenith range of $80^{\circ}$ and the corresponding profiles defined as Fig. 11(b). The values of input coefficients are shown in Table III. The solar position $\left(\theta_{\mathrm{s}}, \varphi_{\mathrm{s}}\right)$ is calculated from the local time and geographic position of the experiment site. Canopy brightness temperature components (Ts $, T s o, T v)$ and canopy geometry parameters $(H, h, a, L, \mathrm{LAI})$ come from the measurement at the time. Leaf dimension $m$ was derived from plant average width, whose value was equal to the inverse of one-half plant width. The selection of the attenuation parameter was based on the optimizing the shape of modeled DBT. By using an optimized attenuation parameter with a value $1.3 \tau$, the polar map fits those of measurements well. As mentioned earlier, corresponding $\lambda(\theta) G(\theta)$ is the interpretation from the line for LAI $=1$ and 2 in Fig. 2. The reason that the input optimized attenuation parameter needs a factor of 1.3 is still under investigation. One of the reasons is the simplification of canopy geostructure. Unlike the canopy in natural conditions, all the leaves in the model are concentrated in the hedgerows, which make more the gaps for the same LAI value. According to the research of Espana et al. [32], the extinction parameter $k(\theta)$ of maize canopy at the nadir is in the 
a

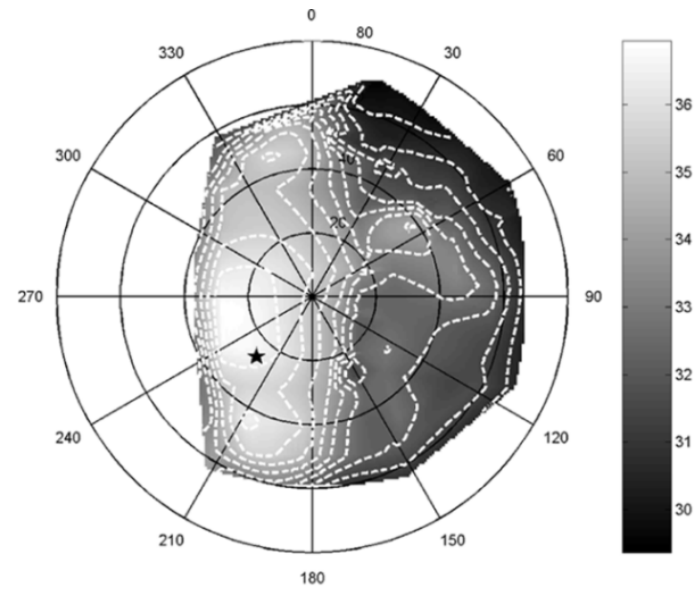

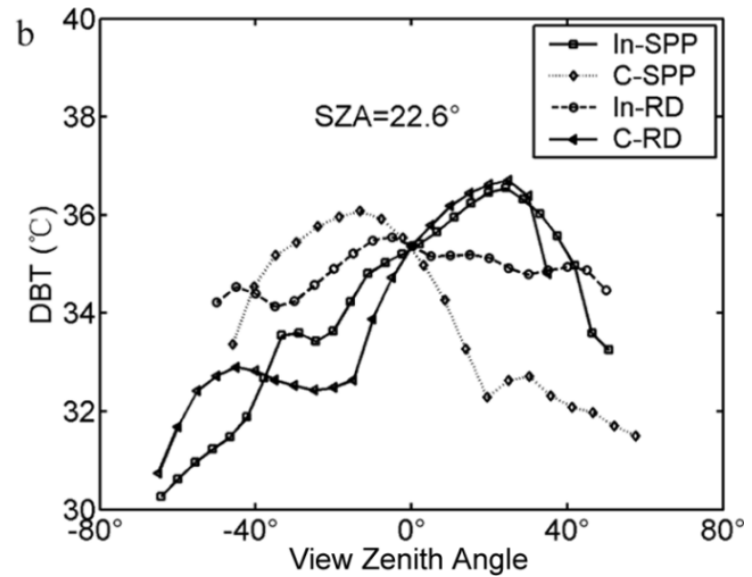

Fig. 11. Field DBT at $13 \mathrm{~h} 10$ of local time on June 24, 1999. At the time, solar zenith and azimuth were $25.6^{\circ}$ and $222.6^{\circ}$, respectively. (a) Polar map for whole viewing. (b) Four profiles in and crossing solar principal plane.

a

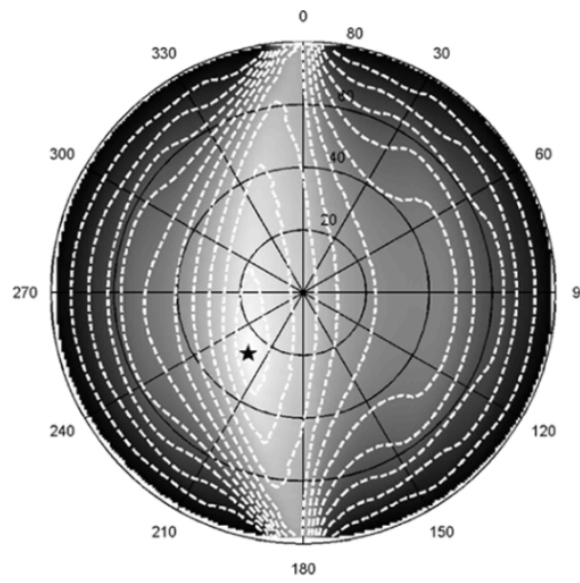

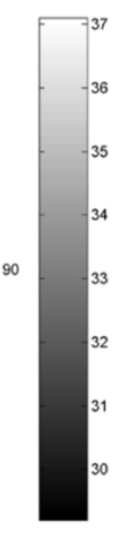

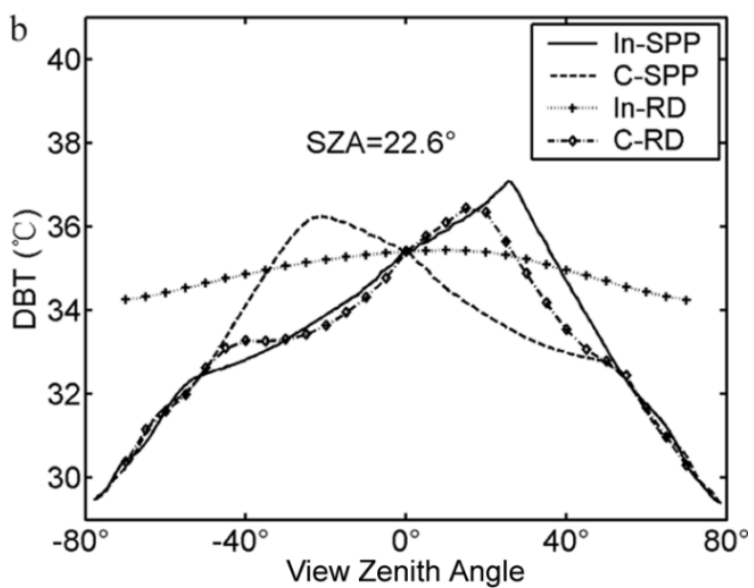

Fig. 12. Simulation of maize field DBT at 13:10 of local time on June 24, 1999.

range of $0.27-0.37$. Here, we calculated its value at the nadir direction from $1.3 \tau$ by combining $(8)$ and (12)

$$
P(0)=e^{-k(0) \mathrm{LAI}}=\frac{\left(L-a+a e^{-\tau(0) b}\right)}{L} .
$$

By using the parameters in Table III, the value of $k(0)$ is 0.35 , which is within the range of the attenuation parameter provided by Espana et al. [32]. This value is also in good agreement with the results of Andrieu et al. [44], who measured an average value of 0.34. So the factor is applied in further simulations.

Fig. 13 shows the comparisons of measured and simulated profiles in solar plane [Fig. 13(a)], across the solar plane [Fig. 13(b)], in the row direction [Fig. 13(c)], and across the row [Fig. 13(d)]. The coincidence of measured and simulated data is presented, especially in the trend of curves. The maximum difference is about $2{ }^{\circ} \mathrm{C}$ appearing at the backward direction in Fig. 13(d). Fig. 14(a) and (b) shows, respectively, the histogram of variation distribution and the relation between measured and simulated data. In the histogram, most variations concentrate within the range of $-0.5^{\circ} \mathrm{C}$ to $1^{\circ} \mathrm{C}$. The distribution is Gaussian. In Fig. 14(b), at the high temperature range, the measured TBD is larger than $36{ }^{\circ} \mathrm{C}$. Part of simulated temperature is higher than that of measured, with part of simulated temperature lower. As shown in Fig. 13(a) and (d), these two parts correspond to the hot spot area and the hottest area just over the hot spot in the map. In the middle temperature range, there appear two other peaks of the measured DBT, $32{ }^{\circ} \mathrm{C}$ and $34{ }^{\circ} \mathrm{C}$. One is higher than the simulated DBT, with another lower. This could be explained by the profiles in Fig. 13(b). The modeled DBT is higher than the measured DBT in forward side and lower in backward scattering direction. Some biases exist in the simulation of maize field DBT. Besides these peaks, there are still other variations in the map. We like to ascribe these to the measured data that have not provided a perfect DBT description. For a canopy in natural condition, the status of the plants is not the same. There exists a difference in the view conducted by a camera with a $71^{\circ} \mathrm{FOV}$ at $20 \mathrm{~m}$ above the crop. This should be a possible error factor in the validation. Finally, the correlation parameter is of 0.90 with a root mean squre error of $0.62{ }^{\circ} \mathrm{C}$.

More comparisons have been conducted using the measured data on the same day but at different time. Fig. 15 shows two comparisons of the modeled and measured DBT at $13 \mathrm{~h} 55$ [Fig. 15(a)] and 16h02 [Fig. 15(b)] of local time, respectively. At $13 \mathrm{~h} 55$ on June 24 , the input solar position was $33.7^{\circ} / 241^{\circ}$, the component brightness temperatures were $44.6^{\circ} \mathrm{C}(T s b)$, $30.6{ }^{\circ} \mathrm{C}(T s s), 26.9^{\circ} \mathrm{C}(T v)$, and other input parameters were not changed. Although there exists a big difference between the 
TABLE III

INPUT PARAMETER VALUES FOR GORT MODEL

\begin{tabular}{ccccccccccc}
\hline $\begin{array}{c}\theta_{s} \\
\text { (degree) }\end{array}$ & $\begin{array}{c}\varphi_{s} \\
(\text { degree })\end{array}$ & $\begin{array}{c}T_{s b} \\
\left({ }^{\circ} \mathrm{C}\right)\end{array}$ & $\begin{array}{c}T_{s o} \\
\left({ }^{\circ} \mathrm{C}\right)\end{array}$ & $\begin{array}{c}T_{v} \\
\left({ }^{\circ} \mathrm{C}\right)\end{array}$ & $\begin{array}{c}H \\
(\mathrm{~m})\end{array}$ & $\begin{array}{c}H \\
(\mathrm{~m})\end{array}$ & $\begin{array}{c}a \\
(\mathrm{~m})\end{array}$ & $\begin{array}{c}L \\
(\mathrm{~m})\end{array}$ & $\begin{array}{c}M \\
\left(\mathrm{~m}^{-1}\right)\end{array}$ & $L A I$ \\
\hline 25.6 & 222.5 & 42.3 & 30.9 & 29.2 & 0.8 & 0.15 & 0.46 & 0.8 & 5 & 1.73 \\
\hline
\end{tabular}
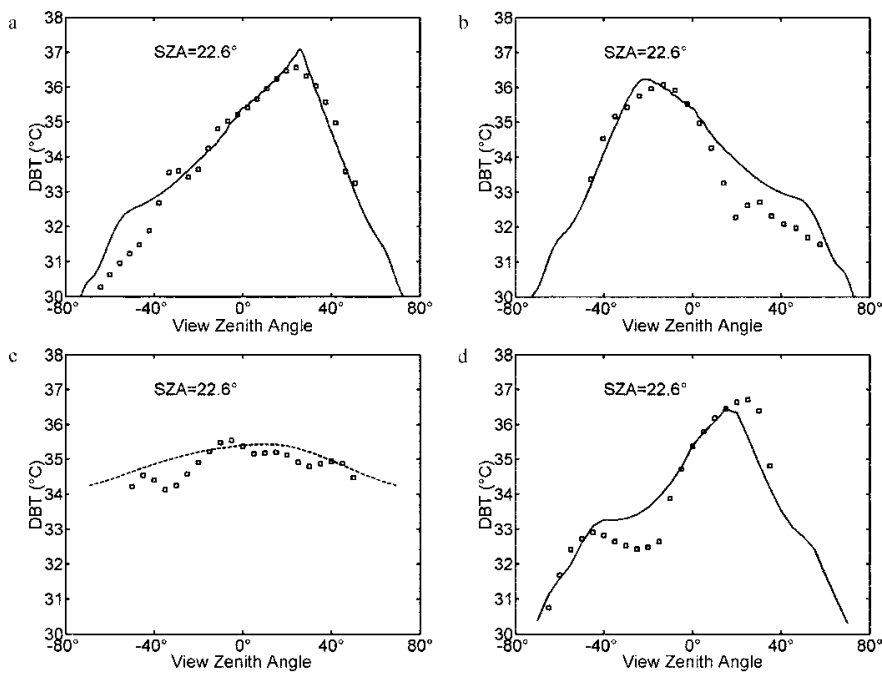

Fig. 13. Comparisons of the modeled DBT profiles with measured data.
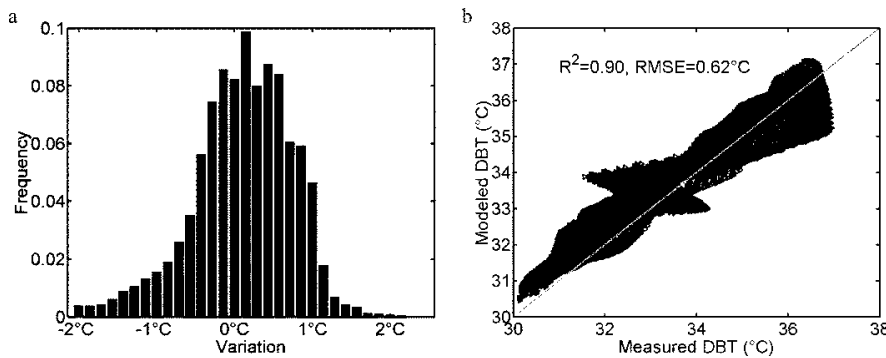

Fig. 14. Difference between two polar maps for (a) measured and simulated data and (b) the analysis of error distribution.
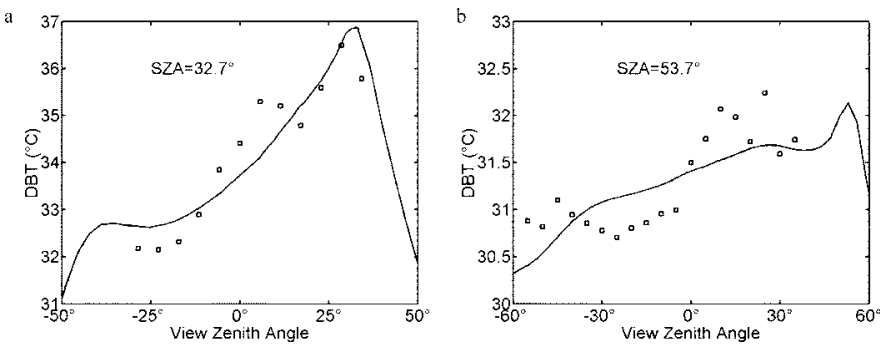

Fig. 15. Comparison of (solid line) the modeled DBT in solar principal plane with the measurement at two different time of (a) $13 \mathrm{~h} 55$ and (b) $16 \mathrm{~h} 02$ of local time on the same day of June 24.

measured data at $13 \mathrm{~h} 10$ [Fig. 13(a)] and 13h55, the simulation still stay a high agreement with the measurement. However, some problems appear in the comparison with the measurement at $16 \mathrm{~h} 02$. When the input solar position was $54^{\circ} / 269^{\circ}$, the component brightness temperatures were $39.4{ }^{\circ} \mathrm{C}(T s b), 29.2^{\circ} \mathrm{C}$ $(T s s), 29.2^{\circ} \mathrm{C}(T v)$. The shaded soil and the vegetation were of the same brightness temperature. The measured data fluctuated within a wide range. This is due to the mix of the sunlit and the shaded soil and the heterogeneity of the canopy spatial thermal

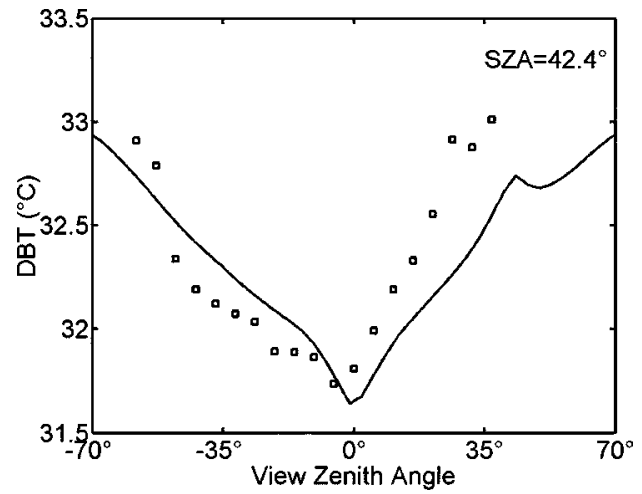

Fig. 16. Comparison of (solid line) the modeled DBT in solar principal plane with the measurement at $14 \mathrm{~h} 5$ on July 20 when LAI was 4.5 .

radiation. When the sun is in the plane crossing the row with a large solar zenith angle, solar light has to pass through the hedgerows before reaching the soil among the hedgerows, so the sunlit and shaded soil mixed, which induces the component brightness temperatures to have a complex distribution and a large variation. The three-component assumption in the model needs more concerns, but it may not be available yet. In the meantime, the heterogeneity of the canopy seriously influences the distribution of the thermal radiation distributions by gap fractions.

With the increase of biomass, the DBT shows new feature due to the change of the order of component brightness temperatures and the change of gap fraction distribution. Fig. 16 shows the comparison of the modeled DBT in solar principal plane with the measurement at $14 \mathrm{~h} 5$ on July 20 when the LAI was 4.5 , the averaged plant height and width was 1.7 and $0.8 \mathrm{~m}$, and the field coverage was 0.67 . In the simulation, the input solar position was $42.4^{\circ} / 251^{\circ}$, the hedgerow width is $0.65 \mathrm{~m}$, the component brightness temperatures were $32.2^{\circ} \mathrm{C}(T s b), 28.1^{\circ} \mathrm{C}$ (Tso), $32^{\circ} \mathrm{C}(T v)$ of which the vegetation temperature is comparable to the sunlit soil. This is understandable because most solar light is intercepted by the vegetation. Thus, the soil temperature is more influenced by the local energy exchanging within the canopy, which makes the temperature of soil lower than that of the low- and middle-density canopy. From the prediction of the model, a minimum temperature is at the nadir. The DBT changes sharper in backward scattering direction than in the forward direction, with a small hot spot in the sun direction. Comparing with the measured DBT, a slight less estimation of DBT occurs in the backscatter direction. We attribute this error to the limitation of this model for the fully covered row structure canopy. The simplified estimation of gap fraction may cause the bias in the simulation of the DBT. Moreover, the three-component classification is not accurate. There exists a normal distribution of each component brightness temperature instead of a unique value [41]. One of the reasons is the difference in the thermal property. With a high thermal inertia value, the shaded regions 
of soil do not heat up to full temperature as soon as they are sunlit, and sunlit regions of soil do not cool down to the temperature as soon as they are shaded.

\section{CONCLUSION}

This paper provides a simple hybrid geometric optical and radiative transfer model to simulate row crop DBT based on a series of assumptions on canopy geometrical architecture, optical properties, and temperature distributions. Compared with previous GORT models, the new GORT model considered both the row structure effect and the hot spot effect at the same time by calculating the canopy gap distributions between and within the hedgerows.

The model revealed the combined influences of canopy geometric structure, brightness temperature distribution and the sun-view geometry on the canopy DBT. The hot spot and the hot stripe around the hot spot appear in the simulated DBT. The hot spot appears as a temperature peak in the backward scattering direction of solar radiation. The hot stripe, around the hot spot, displays a core shape along the row direction in the polar map caused by row structure. These two features could be explained by gap distribution between and within the hedgerows and the changes of component temperatures. However, the position of the maximum DBT may not be at the hot spot due to the changes of input parameters. Further analysis shows the modeled DBT fits well to the measured data with a modification of input data. The model has captured the main features of the maize field DBT and can explain clearly the coupling of the hot spot and the row structure effect. Slight difference between the measurement and modeling is still under investigation.

\section{REFERENCES}

[1] R. D. Jackson, R. J. Reginato, and S. B. Idso, "Wheat canopy temperature: A practical tool for evaluating water requirement," Water Resour. Res., vol. 13, pp. 651-656, 1977.

[2] R. D. Jackson, R. J. Reginato, P. J. J. Pinter, and S. B. Idso, "Plant canopy information extraction from composite scene reflectance of row crops," Appl. Opt., vol. 18, pp. 3775-3782, 1979.

[3] B. Seguin and B. Itier, "Using midday surface temperature to estimate daily evaporation from satellite thermal IR data," Int. J. Remote Sens., vol. 4, pp. 371-383, 1983.

[4] M. A. Friedl, "Modeling land surface fluxes using a sparse canopy model and radiometric temperature measurements," J. Geophys. Res., vol. 100, pp. 25 435-25 446, 1985.

[5] L. Prévot, "Modélization des echanges radiatifs au sein des couverts végétaux. Application a la télédétection. Validation sur un couvert de maïs," Doctoral thesis, Univ. Paris VI, Paris, France, 1985.

[6] M. S. Moran, T. R. Clarke, Y. Inove, and A. Vidal, "Estimating crop water deficit using the relationship between surface-air temperature and spectral vegetation index," Remote Sens. Environ., vol. 49, pp. 246-263, 1994

[7] J. M. Norman, M. Divakarla, and N. S. Goel, "Algorithms for extracting information from remote thermal-IR observations of the earth's surface," Remote Sens. Environ., vol. 51, pp. 157-168, 1995.

[8] N. Morrow and M. A. Friedl, "Modeling biophysical controls on land surface temperature and reflectance in grassland," Agricult. Forest Meteorol., vol. 92, pp. 147-161, 1998.

[9] M. Weiss, F. Baret, M. Leroy, A. Bégué, O. Hautecoeur, and R. Santer, "Hemisphrical reflectance and albedo estimation from the accumulation of across-track sun-synchronous satellite data," J. Geophys. Res., vol. 104, pp. 22 221-22 232, 1999.

[10] L. P. Lagouarde, H. Ballans, P. Moreau, D. Guyon, and D. Coraboeuf, "Experimental study of brightness surface temperature angular variations of maritime pine (pinus pinaster) stands," Remote Sens. Environ., vol. 72, pp. 17-34, 2000.
[11] D. S. Kimes, "Remote sensing of row crop structure and component temperatures using directional radiometric temperatures and inversion technique," Remote Sens. Environ., vol. 13, pp. 33-55, 1983.

[12] K. T. U. Paw, S. L. Ustin, and C. Zhang, "Anisotropy of thermal infrared exitance in sunflower canopies," Agricult. Forest Meteorol., vol. 47, pp. 189-203, 1989.

[13] W. P. Kustas, "Ground and aircraft infrared observations over a partiallyvegetated area," Int. J. Remote Sens., vol. 11, pp. 409-427, 1990.

[14] J. P. Lagouarde, Y. H. Kerr, and Y. Brunet, "An experimental study of angular effects on surface temperature for various plant canopies and bare soils," Agricult. Forest Meteorol., vol. 77, pp. 167-190, 1995.

[15] J. Otterman, T. W. Brakke, M. Fuchs, V. Lakshmi, and M. Cadeddu, "Longwave emission from a plant/soil surface as a function of the view direction: Dependence on the canopy architecture," Int. J. Remote Sens., vol. 20, pp. 2195-2201, 1999.

[16] D. S. Kimes, "Remote sensing of temperature profiles in vegetation canopies using multiple view angle and inversion techniques," IEEE Trans. Geosci. Remote Sensing, vol. GE-19, pp. 85-90, Jan. 1981.

[17] A. J. Smith, J. R. Ballard, and J. A. Pedelty, "Effect of three-dimensional canopy architecture on thermal infrared exitance," Opt. Eng., vol. 36, pp. 3093-3100, 1997.

[18] W. C. Snyder, Z. M. Wan, Y. L. Zhang, and Y. L. F. Y. Z., "Thermal infrared (3-14 $\mu \mathrm{m})$ bidirectional reflectance measurements of sand and soils," Remote Sens. Environ., vol. 60, pp. 101-109, 1997.

[19] W. C. Snyder and Z. Wan, "BRDF models to predict spectral reflectance and emissivity in the thermal infrared," IEEE Trans. Geosci. Remote Sensing, vol. 36, pp. 214-225, Jan. 1998.

[20] J. P. Gastellu-Etchegorry, F. Gascon, V. Demarez, M. J. Lefevre, P. Guillevic, N. Benech, and V. Mathiaud, "DART: A 3-D model of satellite images and surface radiation budget," presented at the 8th Int. Symp. Physical Measurements Signatures in Remote Sensing, Aussois, France, Jan. 8-12, 2001.

[21] C. François, C. Ottlé, and L. Prévot, "Analytical parameterization of canopy directional emissivity and directional radiance in the thermal infrared. Application on the retrieval of soil and foliage temperature using two directional measurements," Int. J. Remote Sens., vol. 12, pp. 2587-2621, 1997.

[22] G. Yan, M. Friedl, X. Li, J. Wang, C. Zhu, and A. H. Strahler, "Modeling directional effects from nonisothermal land surfaces in wideband thermal infrared measurements," IEEE Trans. Geosci. Remote Sensing, vol. 39, pp. 1095-1099, May 2001.

[23] J. L. Hatfield, J. P. Millard, and R. C. Goettelman, "Variability of surface temperature in agricultural fields of central California," ISPRS J. Photogramm. Remote Sens., vol. 48, pp. 1319-1325, 1982.

[24] J. W. Wilson, "Stand structure and light penetration. 1-Analysis by points quadrats," J. Appl. Ecol., vol. 2, pp. 383-390, 1965.

[25] T. Nilson and A. Kuusk, "A theoretical analysis of the frequency of gaps in plant stands," Agricult. Forest Meteorol., vol. 8, pp. 25-38, 1971

[26] L. H. Allen, "Model of light penetration into a wide-row crop," Agronom. J., vol. 66, pp. 41-47, 1974.

[27] S. Cohen, M. Fuchs, S. Moreshet, and Y. Cohen, "The distribution of leaf area, radiation, photosynthesis, and transpiration in a Shamouti orange hedgerow orchard: Part II. Photosynthesis, transpiration, and the effect of row shape and direction," Agricult. Forest Meteorol., vol. 40, pp. 145-162, 1987.

[28] X. W. Li and A. H. Strahler, "Modeling the gap probability of a discontinuous vegetation canopy," IEEE Trans. Geosci. Remote Sensing, vol. GE-26, pp. 161-170, Mar. 1988.

[29] A. Ganis, "Radiation transfer estimate in a row canopy: A simple procedure," Agricult. Forest Meteorol., vol. 88, pp. 67-76, 1997.

[30] M. Tsubo and S. Walker, "A model of radiation interception and use by a maize-bean intercrop canopy," Agricult. Forest Meteorol., vol. 10, pp 203-215, 2002.

[31] J. Ross, "Radiative transfer in plant communities," Veg. Atmos., vol. 1, pp. 13-52, 1975.

[32] B. M. L. Espana, F. Baret, M. Chelle, F. Aries, and B. Andrieu, "A dynamic model of maize 3D architecture: Application to the parameterization of the clumpiness of the canopy," Agronomie, vol. 18, pp. 609-626, 1998.

[33] G. S. Campbell, "Extinction coefficients for radiation in plant canopies calculated using an ellipsoidal inclination angle distribution," Agricult. Forest Meteorol., vol. 36, pp. 317-321, 1986.

[34] _ - "Derivation of an angle density function for canopies with ellipsoidal leaf angle distributions," Agricult. Forest Meteorol., vol. 49, pp. 173-176, 1990. 
[35] J. E. Jackson and J. W. Palmer, "Interception of light by model hedgerow orchards in relation to latitude, time of year and hedgerow configuration and orientation," J. Appl. Ecol., vol. 9, pp. 341-358, 1972.

[36] J. W. Palmer, "Diurnal light interception and a computer model of lighten interception by a hedgerow apple orchard," J. Appl. Ecol., vol. 14, pp. 601-614, 1977.

[37] N. Gijzen and J. Goudriaan, "A flexible and explanatory model of light distribution and photosynthesis in row crops," Agricult. Forest Meteorol., vol. 48, pp. 1-20, 1989.

[38] M. J. Mariscal, F. Orgaz, and F. J. Villalobos, "Modeling and measurement of radiation interception by olive canopies," Agricult. Forest Meteorol., vol. 100, pp. 183-197, 2000.

[39] J. M. Norman and F. Becker, "Terminology in thermal infrared remote sensing of natural surfaces," Remote Sens. Rev., vol. 12, pp. 159-173, 1995.

[40] A. Olioso, "Estimating the difference between brightness and surface temperature for a vegetal canopy," Agricult. Forest Meteorol., vol. 72, pp. 237-242, 1995.

[41] T. Yu, X. Gu, G. Tian, M. Legrand, J. F. Hanocq, R. Bosseno, and Y. Lv, "Classification of brightness temperature components," in Proc. IGARSS, Toulouse, France, July 21-25, 2003.

[42] A. Kuusk, "The hot spot effect of a uniform vegetative cover," Sov. J. Remote Sens., vol. 3, pp. 645-658, 1985.

[43] W. Ni, X. Li, C. E. Woodcock, M. R. Caetano, and A. H. Strahler, "An analytical hybrid GORT model for bidirectional reflectance over discontinuous plant canopies," IEEE Trans. Geosci. Remote Sensing, vol. 37, pp. 987-999, Mar. 1999

[44] B. Andrieu, J. M. Allir, and K. Jaggard, "Ground cover and leaf area index of maize and sugar beet crops," Agronomie, vol. 37, pp. 315-321, 1997. 